\title{
Design of Stable Palladium-Based Zeolite Catalysts for Complete Methane Oxidation by Post-Synthesis Zeolite Modification
}

\author{
Andrey W. Petrov, ${ }^{1,2}$ Davide Ferri, ${ }^{1}$ Oliver Kröcher,,${ }^{1,3,}{ }^{*}$ Jeroen A. van Bokhoven ${ }^{1,2, *}$ \\ 1 - Paul Scherrer Institut, CH-5232 Villigen PSI, Switzerland \\ 2 - ETH Zurich, Institute for Chemical and Bioengineering, CH-8093 Zurich, Switzerland \\ 3 - Ecole polytechnique fédérale de Lausanne (EPFL), Institute of Chemical Sciences and \\ Engineering, CH-1015 Lausanne, Switzerland \\ * Corresponding authors \\ oliver.kroecher@psi.ch +41563102066 \\ jeroen.vanbokhoven@chem.ethz.ch +41446325542
}

ORCID

Davide Ferri, 0000-0002-9354-5231

Oliver Kröcher, 0000-0002-7268-7257

Jeroen A. van Bokhoven, 0000-0002-4166-2284

This document is the accepted manuscript version of the following article:

Petrov, A. W., Ferri, D., Kröcher, O., \& van Bokhoven, J. A. (2019). Design of Stable PalladiumBased Zeolite Catalysts for Complete Methane oxidation by Postsynthesis Zeolite Modification. ACS Cata7ysis, 9(3), 2303-2312. https://doi.org/10.1021/acscata1.8b04486 


\begin{abstract}
Catalytic methane oxidation is used in exhaust gas aftertreatment to reduce methane emissions from lean-burn natural gas vehicles as well as in stationary combustion processes. $\mathrm{Pd} /$ zeolite catalysts provide high activity for this reaction, but they deactivate rapidly under reaction conditions and in the presence of steam due to extensive palladium nanoparticle sintering, which is a common deactivation pathway for supported catalysts. Understanding the origin of this phenomenon is crucial for improving the performance of such materials. In this work, we identify all stability and activity descriptors of $\mathrm{Pd} /$ zeolites fully exchanged with sodium. Based on these descriptors we design an active and stable catalyst using the synthetic approach which comprises formation of mesopores in the zeolite by mild desilication, removal of surface and extra-framework aluminum by selective dealumination and complete sodium post-exchange. This allows to turn unstable $\mathrm{Pd} / \mathrm{H}-\mathrm{ZSM}-5$ into a highly active sintering-resistant hierarchical $\mathrm{Pd} / \mathrm{Na}-\mathrm{ZSM}-5$ for the demanding reaction of complete methane oxidation. This synthetic procedure can be applied to other zeolites to enhance stability of supported catalysts that are prone to sintering.
\end{abstract}

Keywords: methane oxidation, exhaust aftertreatment, palladium, hierarchical zeolite, desilication, constrained mesopores 


\section{Introduction}

Lean-burn natural gas engines significantly reduce carbon dioxide emissions and increase the overall fuel efficiency both in stationary and automotive applications. The advantages of natural gas as a fuel include lowest hydrogen-to-carbon ratio among all hydrocarbons, high abundance and an already existing distribution network. Moreover, methane can also be produced from biogenic sources enabling a smooth transition to a renewable energy system by substituting increasing shares of natural gas by biomethane. ${ }^{1}$ The main concern about methane as a fuel is that state-of-the-art catalysts lack low-temperature activity and long-term stability, leading to methane emissions in the exhaust gas. ${ }^{2-6}$ Typical methane oxidation catalysts comprising a noble metal, preferably palladium highly dispersed over a support material, ${ }^{6-17}$ suffer from rapid deactivation under reaction conditions induced by the active phase sintering. ${ }^{18-21}$

Stabilization of metal nanoparticles in the constrained inner space of a support has attracted increasing attention in recent years. ${ }^{22-26}$ Such approach allows to physically encage metal particles, allowing the reactants to diffuse through the bottle-neck pores, which are nonpermeable to the constrained metal nanoparticles due to size restrictions. This approach is especially relevant for expensive precious metal-based catalysts, allowing to drive down the materials costs by decreasing the amount of the active metal. In addition, enhanced stability prolongs the operation time, further improving the economics of the process. Numerous support materials and encapsulation methods have been reported for various metals. For instance, in the case of precious metals, Seo et al. encapsulated palladium particles in amorphous silica-alumina by coating the metal nanocrystals. ${ }^{27}$ Post-synthetic zeolite recrystallization was used to produce encapsulated platinum particles in hollow zeolite nanospheres. ${ }^{28}$ A similar result was achieved by alkaline post-synthesis treatment of the zeolite and subsequent impregnation of iron and platinum. ${ }^{25}$ Martinez et al. used carbon nanoparticles as hard template to obtain mesoporous hollow zeolite and then deposited palladium by impregnation. ${ }^{29}$ Cargnello et al. recently obtained superior methane oxidation activity over two-nanometer palladium nanoparticles coated by ceria and supported on alumina. ${ }^{30}$ Palladium particles similarly coated with titania also yielded promising results. ${ }^{31}$ Athough these approaches led to enhanced activity and stability of encapsulated metal nanoparticles, complete prevention of nanoparticle migration could not be achieved, ${ }^{32}$ thus requiring further advancements in understanding of what causes sintering and mitigation by novel synthesis strategies. 
The variety of available strategies requires a rational approach to the selection of appropriate synthesis methods and materials. Metal nanoparticles should be very small, between one and two $\mathrm{nm}$, to provide high surface area and reactivity $2,13,30$ and they should be densely packed to minimize the dimensions of the catalyst bed. A zeolite is an attractive material for encapsulation of small metal particles, as the micropores in the walls have a uniform diameter below one nanometer, which is in most cases sufficient for reactants and products to freely diffuse, but prevents the mobility of the particles of a few nanometer in diameter. The voids (mesopores) in the zeolite crystals would have an ideal size, which is comparable to the diameter of a metal nanoparticle to reach maximum loading per unit of volume. Finally, zeolites possess high integrity and stability and to large extent stand high temperatures typical for catalytic applications. ${ }^{33}$

Mesopores can be obtained in zeolites by various methods, such as hard and soft dual templating, recrystallization, steaming, desilication, dealumination and others. ${ }^{34-39}$ Desilication by alkaline treatment yields well-defined mesopores while preserving high crystallinity and integrity of the zeolite matrix. ${ }^{37-38}$ The mesopore quality (diameter, shape and connectivity) can be controlled carefully by modifying the synthesis conditions and using additional reactants. Fodor et al. $^{37}$ and Milina et al. ${ }^{38}$ described zeolites with constrained mesopores obtained by alkaline treatment in the presence of an organic template. While being not ideal for mass transfer limited reactions, where open mesopores are preferred, such material perfectly matches the requirements of a hierarchically structured metal-zeolite catalyst with encapsulated particles in the voids.

Dealumination with mineral acids also produces secondary pores in zeolites upon dissolution of silicon from the defect areas of the zeolite at low $\mathrm{pH}^{40}$ and due to partial structural collapse of excessively dealuminated low silica-zeolites. ${ }^{41}$ This method, however, significantly changes the acid properties and aluminum distribution within the zeolite. Aluminum removal from the zeolite can be controlled by variation of the acid and the treatment conditions. For instance, the selective removal of aluminum from the external surface of the small-pore zeolites occurs upon the treatment with organic acids like oxalic, tartaric or acetic, since the aluminum salts of these acids are too bulky to be formed inside the micropores. ${ }^{42-43}$

There is high demand for improving the activity and especially the stability of palladiumbased catalysts for the demanding reaction of complete methane oxidation and the above described strategy could be used to achieve this.

Several publications included comparison between sodium and proton forms of palladium/zeolite catalysts for complete methane oxidation. For example, Maeda et al. 
compared $\mathrm{Pd} / \mathrm{H}-\mathrm{MOR}$ and $\mathrm{Pd} / \mathrm{Na}-\mathrm{MOR}$ with various $\mathrm{Si} / \mathrm{Al}$ ratios and concluded that very high $\mathrm{Si} / \mathrm{Al}$ ratio (260) as well as the presence of sodium cations in the zeolite negatively affected both activity and stability. ${ }^{44-45}$ On the contrary, earlier works showed that the activity of $\mathrm{Pd} / \mathrm{Na}$-zeolites can be positively correlated with the $\mathrm{Na} / \mathrm{Pd}$ ratio. ${ }^{21}, 44$ In the abovementioned works sodium was either initially present in the parent zeolite, or was added by ion-exchange prior to the exchange with palladium. The latter treatment produces only partlyexchanged zeolites. For example, the conventional ion-exchange procedure led to only $46 \%$ cation exchange in the case of mordenite with the $\mathrm{Si} / \mathrm{Al}$ ratio of $51 .{ }^{44}$ Recently, we showed that dealuminated $\mathrm{Pd} / \mathrm{H}-\mathrm{MOR}$, when completely exchanged with sodium to remove all residual acid sites, yields a highly active and stable catalyst. ${ }^{46}$ This was achieved by suppressing Ostwald ripening induced by the zeolite acidity and stabilization of palladium nanoparticles within the mesopores of the support, which were displaced from the zeolite acid sites by sodium.

In this work, we demonstrate the importance of fine-tuning the properties of zeolite supported catalysts by presenting a novel synthesis strategy, which yields methane oxidation catalysts of unprecedented activity and stability, explains the discrepancy in literature about the role of sodium cations and extends the knowledge about stability descriptors of $\mathrm{Pd} / \mathrm{Na}$-zeolites. With the goal of obtaining stable encaged palladium nanoparticles in the zeolite, we introduce a synthetic approach comprising consecutive desilication, selective dealumination, palladium exchange and removal of residual zeolite acidity by post-exchanging sodium and turn unstable Pd/H-ZSM-5 into highly active and stable mesoporous dealuminated Pd/Na-ZSM-5. We show that this synthetic procedure can be applied to other zeolite frameworks (MOR, BEA) and be used with various charge-balancing cations ( $\mathrm{Na}, \mathrm{K}$ and $\mathrm{Cs}$ ) to enhance the stability of supported palladium catalysts.

\section{Experimental}

\subsection{Catalyst synthesis}

Zeolite ZSM-5 (SM-27, $\mathrm{NH}_{4}{ }^{+}$-form, $\mathrm{Si} / \mathrm{Al}=13$, Clariant) was calcined to produce the H-form (denoted as $\mathrm{H}-\mathrm{Z}$ ) and then subjected to various acid treatments (hydrochloric, nitric and oxalic acids) and base-acid treatments, which are summarized in Figure 1, with the goal to modify the aluminum distribution and the pore structure. The base treatment was carried out at $65{ }^{\circ} \mathrm{C}$ for $30 \mathrm{~min}$. First, the zeolite powder $(5 \mathrm{~g})$ was added to the preheated magnetically stirred mixture $(100 \mathrm{ml})$ containing sodium hydroxide $(0.2 \mathrm{M})$ and tetrapropylammonium bromide (TPABr, 0.2 M). To control the desilication time precisely, after $30 \mathrm{~min}$ the slurry 
was taken out of the water bath and diluted with cold deionized water $(200 \mathrm{ml})$. The solid component was then separated, washed thoroughly with deionized water until the $\mathrm{pH}$ value was not below 8 , dried at $120{ }^{\circ} \mathrm{C}$ for $24 \mathrm{~h}$ and calcined in a muffle oven at $600{ }^{\circ} \mathrm{C}$ for $2 \mathrm{~h}$. Acid treatments were performed under a reflux at $80{ }^{\circ} \mathrm{C}$ for $4 \mathrm{~h}$ followed by washing with deionized water and drying as described above. After these pretreatments, the obtained materials were ion-exchanged with the required amount of $\left[\mathrm{Pd}\left(\mathrm{NH}_{3}\right)_{4}\right]\left(\mathrm{NO}_{3}\right)_{2}$ solution $(\mathrm{pH}=$ 6) at room temperature for $24 \mathrm{~h}$ to obtain a nominal $1 \mathrm{wt} \%$ loading of palladium. After drying at $120{ }^{\circ} \mathrm{C}$ for $24 \mathrm{~h}$, the final $\mathrm{Pd} / \mathrm{H}-\mathrm{ZSM}-5$ catalysts were obtained by calcination at $500{ }^{\circ} \mathrm{C}$ for $2 \mathrm{~h}$ at the heating rate of $2{ }^{\circ} \mathrm{C} / \mathrm{min}$ to ensure a high dispersion of $\mathrm{PdO}$ nanoparticles. ${ }^{47-49} \mathrm{Fully}$ sodium-exchanged Pd/Na-ZSM-5 catalysts were obtained by titrating the residual acid sites of the parent Pd/H-ZSM-5 catalysts with a sodium bicarbonate solution $(0.02 \mathrm{M})$ for $2 \mathrm{~h}$ until the $\mathrm{pH}$ of the slurry did not reach 7.5. The powder was then washed once with deionized water and calcined at $500{ }^{\circ} \mathrm{C}$ for $2 \mathrm{~h}$. The final catalysts were denoted as $\mathrm{Pd} / \mathrm{A}-\mathrm{Bc}$, where " $\mathrm{A}$ " corresponds to the form of the zeolite $\left(\mathrm{H}^{+}\right.$or $\left.\mathrm{Na}^{+}\right)$, "B" identifies whether the zeolite was desilicated (D) or not (Z), and "c" represents the type of acid(s) used in the pretreatment (c hydrochloric, $\mathrm{n}$ - nitric, o-oxalic).

Mordenite zeolite $\left(\mathrm{CZM}-20, \mathrm{H}^{+}\right.$-form, $\mathrm{Si} / \mathrm{Al}=10$, Clariant) was treated identically to ZSM-5, while for zeolite beta $\left(\mathrm{NH}_{4}-\mathrm{BEA}, \mathrm{NH}_{4}{ }^{+}\right.$-form, $\mathrm{Si} / \mathrm{Al}=12$, Clariant $)$ the conditions of postsynthesis modifications were adjusted. Desilication was performed in a $0.1 \mathrm{M}$ sodium hydroxide solution at $45{ }^{\circ} \mathrm{C}$ for $30 \mathrm{~min}$, dealumination was carried out with $0.5 \mathrm{M}$ oxalic acid solution at room temperature for $2 \mathrm{~h}$. The thus obtained supports were consecutively loaded with palladium and sodium as described above. It should be noted that the mordenite sample received for this work was different from that used in our previous study and was not pretreated. 46

\subsection{Catalyst characterization}

The palladium loading as well as the $\mathrm{Si} / \mathrm{Al}$ ratio and the content of sodium in the catalysts were determined by inductively coupled plasma optical emission spectroscopy (ICP-OES) using a Varian VISTA Pro AX instrument. The catalysts were completely digested in the $\mathrm{HCl} / \mathrm{HNO}_{3} / \mathrm{HF}$ mixture (ratio 6:3:1) in a 3000 Anton Paar microwave digestion unit. The textural properties of the support were characterized by argon physisorption at $77 \mathrm{~K}$ using a Quantachrome Autosorb 1 instrument after degassing at $300{ }^{\circ} \mathrm{C}$ for $6 \mathrm{~h}$ to remove water and other adsorbed species. The support surface area was calculated using the Brunauer-Emmett-Teller (BET) method. The pore size distribution in the range from 2 to 
$100 \mathrm{~nm}$ was calculated by fitting the argon physisorption isotherm using the density functional theory (DFT) model from the software package provided by Quantachrome. Scanning transmission electron microscopy (STEM) and secondary electron (SE) images were taken with a Hitachi HD-2700 microscope at the $200 \mathrm{kV}$ acceleration voltage. Particle size distribution was obtained from counting particles in 10-15 STEM images. A Bruker D8 Advance AXS diffractometer with $\mathrm{Cu} \mathrm{K} \alpha$ radiation was used to obtain powder X-ray diffraction (XRD) patterns in the $2 \theta$ range from $10^{\circ}$ to $60^{\circ}$. Solid-state magic angle spinning nuclear magnetic resonance (MAS NMR) ${ }^{27} \mathrm{Al}$ spectra were recorded at $10 \mathrm{kHz}(1024$ accumulations) on a Bruker Avance $400 \mathrm{MHz}$ spectrometer with ammonium aluminum sulfate dodecahydrate $\left(\mathrm{AlNH}_{4}\left(\mathrm{SO}_{4}\right)_{2} \cdot 12 \mathrm{H}_{2} \mathrm{O}\right)$ as the reference. Transmission IR spectra FTIR measurements were carried out on a Nicolet iS50 spectrometer equipped with a DTGS detector. In a typical experiment, $20 \mathrm{mg}$ of the sample was pressed into a self-supported wafer $\left(2 \mathrm{~cm}^{2}\right)$. The sample was placed in a room temperature quartz glass FTIR cell with $\mathrm{KBr}$ windows and dried in vacuum at $400{ }^{\circ} \mathrm{C}$ for $2 \mathrm{~h}$. Then, the sample was cooled to room temperature and the spectrum was recorded (128 scans at a $4 \mathrm{~cm}^{-1}$ resolution). The background was subtracted using the OMNIC 9.1 software package.

\subsection{Evaluation of catalytic activity}

The activity of the powder catalysts towards methane oxidation was evaluated in a dedicated setup consisting of a quartz-glass plug flow reactor (ID $=6 \mathrm{~mm}$ ), gas flowmeters, heating control and an outlet gas analysis system (InProcess Instruments GAM 400 mass spectrometer). Fragments with the $\mathrm{m} / \mathrm{z}$ ratio of $2\left(\mathrm{H}_{2}\right), 12(\mathrm{C}), 15\left(\mathrm{CH}_{4}\right), 16\left(\mathrm{O}_{2}\right), 18\left(\mathrm{H}_{2} \mathrm{O}\right)$, $28\left(\mathrm{~N}_{2}\right), 30(\mathrm{NO}), 32\left(\mathrm{O}_{2}\right)$ and $44\left(\mathrm{CO}_{2}\right)$ were followed. The exothermic effect of the reaction was minimized by diluting the catalyst (50 mg, 150-200 $\mu \mathrm{m}$ sieve fraction) with cordierite $(150 \mathrm{mg}, 100-150 \mu \mathrm{m})$. Prior to collecting the catalytic data the catalyst was pretreated in the flow of 1 vol. $\% \mathrm{CH}_{4}, 4$ vol. $\% \mathrm{O}_{2}, 95 \% \mathrm{~N}_{2}$ at $550{ }^{\circ} \mathrm{C}$ for $30 \mathrm{~min}$. The reactor was then cooled to $420{ }^{\circ} \mathrm{C}$, and $5 \mathrm{vol} . \%$ of steam was added to the flow to obtain the catalytic stability data in wet feed.

\section{Results and discussion}

\subsection{Performance of the non-treated Pd/H-ZSM-5 and Pd/Na-ZSM-5}

Figure $2 \mathrm{a}$ shows the catalytic stability tests of the variously prepared Pd/ZSM-5 catalysts. Over the non-modified $\mathrm{Pd} / \mathrm{H}-\mathrm{Z}$, methane conversion decreased rapidly upon introduction of 
steam to the $\mathrm{CH}_{4} / \mathrm{O}_{2}$ feed at $420{ }^{\circ} \mathrm{C}$ from $60 \%$ to $13 \%$ within the first three hours followed by slower deactivation. This behavior is associated with the extensive sintering of palladium and the formation of inactive $\mathrm{Pd}(\mathrm{OH})_{2}$ species within the first few hours, followed by a slow degradation of the zeolite through the framework dealumination in the presence of steam. ${ }^{13}$, 19, 49-51 STEM images of the calcined $\mathrm{Pd} / \mathrm{H}-\mathrm{Z}$ and after reaction in the flow of 1 vol.\% $\mathrm{CH}_{4}, 4$ vol. $\% \mathrm{O}_{2}, 5$ vol. $\% \mathrm{H}_{2} \mathrm{O}$, bal. $\mathrm{N}_{2}$ at $420{ }^{\circ} \mathrm{C}$ for $20 \mathrm{~h}$ (referred to as "spent $\mathrm{Pd} / \mathrm{H}-\mathrm{Z}$ ") and the corresponding particle size distributions (Figure 3a,b) confirmed this explanation. The highly dispersed palladium particles with homogeneous size distribution and average diameter of 1.1 $\mathrm{nm}$, present in the calcined catalyst, were virtually absent in the non-modified $\mathrm{Pd} / \mathrm{H}-\mathrm{Z}$ catalyst. The corresponding palladium surface area derived from STEM (Table 1) decreased from $420 \mathrm{~m}^{2} / \mathrm{g}$ for the calcined $\mathrm{Pd} / \mathrm{H}-\mathrm{Z}$ to $70 \mathrm{~m}^{2} / \mathrm{g}$ for the spent $\mathrm{Pd} / \mathrm{H}-\mathrm{Z}$ and was roughly proportional to the activity decrease. Besides the particle sintering, degradation of the zeolite structure also contributes to the catalyst deactivation. Figure 4 a shows the ${ }^{27} \mathrm{Al}$ MAS NMR spectra of the calcined and spent $\mathrm{Pd} / \mathrm{H}-\mathrm{Z}$. Two distinct resonances were observed at chemical shifts of around 0 and $55 \mathrm{ppm}$, the former signal corresponding to the framework-associated octahedral aluminum $\left(\mathrm{Al}_{\text {oct }}\right)$ typical of zeolites in the $\mathrm{H}$-form and the latter to the tetrahedral framework aluminum $\left(\mathrm{Al}_{\mathrm{T}}\right){ }^{52}$ The spent catalyst exhibited broadening and shift to lower values of the $\mathrm{Al}_{\mathrm{T}}$ resonance as a result of the enhanced disorder in the framework aluminum. ${ }^{53}$

Previously, the complete exchange of the residual proton sites of $\mathrm{Pd} /$ zeolite by sodium was shown to improve significantly the stability of the catalyst by preventing both zeolite dealumination and palladium nanoparticle sintering. ${ }^{46}$ However, the sodium-neutralized catalyst $(\mathrm{Pd} / \mathrm{Na}-\mathrm{Z})$ displayed even lower activity and stability than $\mathrm{Pd} / \mathrm{H}-\mathrm{Z}$, becoming completely inactive after $20 \mathrm{~h}$ on stream (Figure 2a). STEM images of the calcined and spent $\mathrm{Pd} / \mathrm{Na}-\mathrm{Z}$ (Figure 3c,d) show that palladium nanoparticles initially exhibited a larger average diameter $(3.5 \mathrm{~nm})$ than in $\mathrm{Pd} / \mathrm{H}-\mathrm{Z}(1.1 \mathrm{~nm})$, which is in agreement with previous observations. ${ }^{46,54}$ In contrast to $\mathrm{Pd} / \mathrm{H}-\mathrm{Z}$, where the activity was proportional to the palladium specific surface area derived from STEM (Table 1), the palladium specific surface area of the spent $\mathrm{Pd} / \mathrm{Na}-\mathrm{Z}\left(70 \mathrm{~m}^{2} / \mathrm{g}\right)$ was only about 1.7 times lower than that of the calcined $\mathrm{Pd} / \mathrm{Na}-\mathrm{Z}$ $\left(120 \mathrm{~m}^{2} / \mathrm{g}\right)$, whereas methane conversion decreased from $60 \%$ to $1 \%$. This suggests that some other factor, besides the particle size, defines the activity and stability of the fully sodiumexchanged Pd/ZSM-5 catalysts.

\subsection{Performance of Pd/H-ZSM-5 and Pd/Na-ZSM-5 after acid modification}


Figure $2 \mathrm{a}$ illustrates the effect of various acid treatments on the catalytic activity of $\mathrm{Pd} / \mathrm{H}$ ZSM-5 and Pd/Na-ZSM-5. The activity and stability of Pd/Na-ZSM-5 after modification by acids improved compared to the non-treated $\mathrm{Pd} / \mathrm{Na}-\mathrm{Z}$ and increased in the series $\mathrm{Pd} / \mathrm{Na}-\mathrm{Zc}<$ $\mathrm{Pd} / \mathrm{Na}-\mathrm{Zn}<\mathrm{Pd} / \mathrm{Na}-\mathrm{Zo}<\mathrm{Pd} / \mathrm{Na}-\mathrm{Zno}$. ICP-OES analysis of the samples (Table 2) shows that acid treatments generally resulted in a modest increase of the $\mathrm{Si} / \mathrm{Al}$ ratio. Nitric acid removed aluminum most efficiently, resulting in the increase of the $\mathrm{Si} / \mathrm{Al}$ ratio from 11.8 to 14.4. Oxalic and hydrochloric acids were less efficient and increased the $\mathrm{Si} / \mathrm{Al}$ ratio to 13.4 and 13.3, respectively. No obvious correlation was found between the catalytic activity of dealuminated Pd/Na-ZSM-5 catalysts and the extent of dealumination. Moreover, the sample treated with oxalic acid $(\mathrm{Pd} / \mathrm{Na}-\mathrm{Zo})$ performed significantly better than the one treated with $\mathrm{HCl}(\mathrm{Pd} / \mathrm{Na}-\mathrm{Zc}$ ), despite the same $\mathrm{Si} / \mathrm{Al}$ ratio (Figure 2). Interestingly, methane oxidation activity over $\mathrm{Pd} / \mathrm{Na}-\mathrm{ZSM}-5$ catalysts positively correlated with the final formal cation exchange level (Table 2). It is claimed that the high exchange capacity of the zeolite can promote the performance of $\mathrm{Pd} /$ zeolite catalysts. ${ }^{55}$ The exchange level value was below $100 \%$ in all cases, suggesting that some aluminum species form sites, which are non-exchangeable with sodium, and that the amount of these non-exchangeable sites varies from sample to sample. Such difference in the zeolite exchange capacity can be explained by the different aluminum speciation in the samples, since this element can exist both as framework and extra-framework species in the zeolite. ${ }^{56-58}$ The former forms a cation-exchange site, whereas the role of the latter is less clear. It can be located elsewhere in the zeolite, including the external surface, or it can form a non-exchangeable site. ${ }^{59-60}$ These species can also function as a cation, occupying ion-exchange sites of the zeolite. ${ }^{61-64}$

Figure $4 \mathrm{~b}$ shows the ${ }^{27} \mathrm{Al}$ MAS NMR spectra of calcined $\mathrm{Pd} / \mathrm{Na}-\mathrm{Z}, \mathrm{Pd} / \mathrm{Na}-\mathrm{Zc}, \mathrm{Pd} / \mathrm{Na}-\mathrm{Zn}$ and $\mathrm{Pd} / \mathrm{Na}-\mathrm{Zo}$. The spectra of the samples washed with nitric $(\mathrm{Pd} / \mathrm{Na}-\mathrm{Zn})$ and oxalic acid $(\mathrm{Pd} / \mathrm{Na}-$ Zo) exhibited sharper $\mathrm{Al}_{\mathrm{T}}$ resonance (55 ppm) and a decreased contribution from distorted tetrahedrally coordinated aluminum and extra-framework aluminum at lower chemical shift (50-20 ppm) compared to $\mathrm{Pd} / \mathrm{Na}-\mathrm{Z}$, indicating that acid treatment removed preferentially defect aluminum species from the zeolite. ${ }^{53}$ On the contrary, no significant difference was observed after pretreatment with hydrochloric acid $(\mathrm{Pd} / \mathrm{Na}-\mathrm{Zc})$. This difference in the state of aluminum, when correlated with the activity of Pd/Na-ZSM-5 catalysts, suggests that their activity and stability can be improved by the extraction of defect aluminum sites. Whereas this argument is sufficient to explain the behavior of $\mathrm{Pd} / \mathrm{Na}-\mathrm{Zo}$ and $\mathrm{Pd} / \mathrm{Na}-\mathrm{Zc}$, alone it cannot fully explain the difference between $\mathrm{Pd} / \mathrm{Na}-\mathrm{Zn}$ and $\mathrm{Pd} / \mathrm{Na}-\mathrm{Zo}$ : the former catalyst exhibits the sharpest $\mathrm{Al}_{\mathrm{T}}$ resonance and a higher $\mathrm{Si} / \mathrm{Al}$ ratio, while the latter is more active and stable. 
This observation suggests that extraction of specific aluminum species by an acid (selective dealumination) might be more important than the overall amount of removed aluminum from the sample.

Transmission IR spectroscopy was used to evaluate the presence of hydroxyl groups (Al-OH) on aluminum species, silanol groups $(\mathrm{Si}-\mathrm{OH})$ and the effect of acid treatments on the intensity of the corresponding signals. ${ }^{52}$, 57-58 The non-modified $\mathrm{Pd} / \mathrm{Na}-\mathrm{Z}$ exhibited three major bands in the $3200-3800 \mathrm{~cm}^{-1}$ spectral region. The first band at $3743 \mathrm{~cm}^{-1}$ corresponds to the terminal Si-OH groups on the external zeolite surface, the band at $3664 \mathrm{~cm}^{-1}$ represents the vibrational mode of Al-OH groups and the broad band at $3520 \mathrm{~cm}^{-1}$ the H-bonded Si-OH groups, the so-called "silanol nests". Modification with hydrochloric acid ( $\mathrm{Pd} / \mathrm{Na}-\mathrm{Zc}$, Figure 5a) caused an increase in the band intensities of both external terminal Si-OH groups (3743 $\left.\mathrm{cm}^{-1}\right)$ and $\mathrm{H}$-bonded $\mathrm{Si}-\mathrm{OH}$ groups $\left(3520 \mathrm{~cm}^{-1}\right)$. These species were likely formed upon the removal of the framework aluminum from the external surface and from the bulk (from the micropores) of the zeolite, respectively. ${ }^{52}$ No obvious change in the amount of Al-OH groups was detected $\left(3664 \mathrm{~cm}^{-1}\right)$ indicating that hydrochloric acid did not remove aluminum associated with Al-OH. Modification with oxalic acid ( $\mathrm{Pd} / \mathrm{Na}-\mathrm{Zo}$, Figure 5c) produced an increase in the signal corresponding to the external terminal Si-OH groups $\left(3743 \mathrm{~cm}^{-1}\right)$. Since the amount of the H-bonded Si-OH groups $\left(3520 \mathrm{~cm}^{-1}\right)$ changed only slightly, it can be concluded that oxalic acid preferentially removed aluminum from the external surface of the zeolite, which is in agreement with previous studies. ${ }^{42-43}$ The signal of Al-OH species at 3664 $\mathrm{cm}^{-1}$ also decreased, indicating their partial removal by oxalic acid. Similarly, pretreatment with nitric acid ( $\mathrm{Pd} / \mathrm{Na}-\mathrm{Zn}$, Figure 5b) resulted in virtually complete removal of $\mathrm{Al}-\mathrm{OH}$ (3664 $\mathrm{cm}^{-1}$ ), which was accompanied by only a slight increase in the signal of the external terminal Si-OH groups $\left(3743 \mathrm{~cm}^{-1}\right)$, suggesting that modest surface dealumination occurred. A decrease in the signal of the "silanol nests" $\left(3520 \mathrm{~cm}^{-1}\right)$ can be explained by the dissolution of framework silicon at low $\mathrm{pH}$, which is known to produce mesopores and to remove some of the H-bonded Si-OH groups. ${ }^{40}$ Due to this effect, it is not possible to identify, whether bulk framework dealumination of the zeolite occurred in the case of $\mathrm{Pd} / \mathrm{Na}-\mathrm{Zn}$, but the highest final $\mathrm{Si} / \mathrm{Al}$ ratio of this sample suggests that nitric acid likely caused significant bulk dealumination of the framework.

Table 2 summarizes the effects of various acid modifications based on the combined data from IR spectroscopy, ${ }^{27}$ Al MAS NMR and ICP-OES. Hydrochloric acid caused nonselective framework dealumination and did not remove EFAL (NMR, IR); nitric acid dissolved distorted tetrahedral aluminum (NMR), silanol nests and partly washed away EFAL 
(IR); and oxalic acid led to selective surface framework dealumination and to a partial removal of EFAL (IR). Combining these conclusions with the catalytic performance of $\mathrm{Pd} / \mathrm{Na}-\mathrm{Z}, \mathrm{Pd} / \mathrm{Na}-\mathrm{Zc}, \mathrm{Pd} / \mathrm{Na}-\mathrm{Zn}$ and $\mathrm{Pd} / \mathrm{Na}-\mathrm{Zo}$ (Figure 2a) it can be argued that aluminum associated with Al-OH (IR), distorted tetrahedral aluminum (NMR), and the surface framework aluminum (IR) have a detrimental effect on the activity and stability of $\mathrm{Pd} / \mathrm{Na}$ ZSM-5 catalysts, while their bulk $\mathrm{Si} / \mathrm{Al}$ ratio is less important. These conclusions are supported by the combined effect of dealumination by nitric and oxalic acids ( $\mathrm{Pd} / \mathrm{Na}-\mathrm{Zno})$, which resulted in an even more active and stable catalyst (Figure 2a). The removal of both EFAL and surface framework aluminum by oxalic acid was complemented by elimination of defect framework aluminum and reduction of a certain amount of silanol groups by nitric acid (Figure $5 \mathrm{c}$ ). The $\mathrm{Si} / \mathrm{Al}$ ratios of $\mathrm{Pd} / \mathrm{Na}-\mathrm{Zn}, \mathrm{Pd} / \mathrm{Na}-\mathrm{Zo}$ and $\mathrm{Pd} / \mathrm{Na}-\mathrm{Zno}$ confirm that even a larger amount of aluminum was extracted from $\mathrm{Pd} / \mathrm{Na}-\mathrm{Zno}$ compared to the individual acid treatments, supporting the conclusion that oxalic and nitric acids removed different aluminum species.

The zeolite modification by an acid did not affect the performance of the catalysts in the proton form: $\mathrm{Pd} / \mathrm{H}-\mathrm{Zno}$ and $\mathrm{Pd} / \mathrm{H}-\mathrm{Z}$ exhibited very similar deactivation behavior (Figure $2 \mathrm{a}$ ). This further supports the previous statement (see section 3.1) that deactivation mechanisms of $\mathrm{Pd} / \mathrm{H}-\mathrm{ZSM}-5$ and Pd/Na-ZSM-5 are distinct. Whereas the dominant deactivation mechanism in $\mathrm{Pd} / \mathrm{H}-\mathrm{ZSM}-5$ is sintering of palladium nanoparticles, $\mathrm{Pd} / \mathrm{Na}-\mathrm{ZSM}-5$ is more sensitive to the properties of the support, notably the aluminum speciation and distribution, and the amount and location of defect sites (Si-OH groups). Alkali and alkali-earth metal oxides are wellknown poisons for oxidation catalysts. ${ }^{65-66}$ Whereas sodium cations located at Brønsted exchange centers of the zeolite do not affect the reactivity of palladium-based catalysts, ${ }^{46}$ excess of $\mathrm{Na}^{+}$or $\mathrm{Al}^{3+}$ cations, which are not attached to the framework could cause chemical poisoning of palladium resulting in complete loss of activity of the catalyst, as observed in the case of $\mathrm{Pd} / \mathrm{Na}-\mathrm{Z}$ catalyst (section 3.1), and by adding an excess of sodium to $\mathrm{Pd} / \mathrm{Na}-\mathrm{MOR}$ catalyst as shown previously. ${ }^{46}$ Additionally, palladium sintering still occurred in the acidpretreated zeolite, as evinced by the STEM images of the calcined and spent $\mathrm{Pd} / \mathrm{Na}-\mathrm{Zno}$ (Figure 3e,f). The palladium surface area derived from STEM reported in Table 1 decreased more than twofold, from 280 to $110 \mathrm{~m}^{2} / \mathrm{g}$. This indicates that although the control of aluminum distribution in $\mathrm{Pd} / \mathrm{Na}-\mathrm{ZSM}-5$ is critical for improving the activity and stability, it is clearly not enough to achieve stable catalyst operation, and that other strategies are needed to successfully prevent Pd particle sintering. 


\subsection{Effect of desilication on the stability and location of palladium in $\mathrm{Pd} / \mathrm{Na}-\mathrm{ZSM}-5$}

Figure $2 \mathrm{a}$ shows that the catalytic activity and stability of consecutively desilicated and dealuminated $\mathrm{Pd} / \mathrm{Na}$-Dno were significantly improved compared to the samples that underwent only dealumination. Clearly, $\mathrm{Pd} / \mathrm{Na}$-Dno exhibited superior sintering-resistance: no difference in palladium particle size distribution and palladium surface area were detected by STEM after aging in reactive feed for $20 \mathrm{~h}$ (Figure 3g,h, Table 1). The X-ray diffraction patterns of $\mathrm{Pd} / \mathrm{Na}-\mathrm{Z}, \mathrm{Pd} / \mathrm{Na}-\mathrm{Zno}$ and $\mathrm{Pd} / \mathrm{Na}-\mathrm{Dno}$ (Figure $\mathrm{S} 1$ ) indicated that after desilication all zeolite reflections exhibited the same intensity as in the starting material, suggesting no change in the crystalline nature of the zeolite. ${ }^{27} \mathrm{Al}$ MAS NMR spectra of the fresh and spent $\mathrm{Pd} / \mathrm{Na}$-Zno (Figure 4c) exhibited a decrease in the intensity of the resonance corresponding to the framework aluminum (55 ppm) and a shift to lower values, indicating a loss of framework aluminum and an increase in its distortion. On the contrary, no significant difference in the spectrum of $\mathrm{Pd} / \mathrm{Na}-\mathrm{Dno}$ was observed before and after reaction (Figue 4d), implying that the stability of the framework tetrahedral aluminum was enhanced after desilication. Additionally, consecutive treatment with base and acid allowed for more complete removal of EFAL species, which were not efficiently washed away with acids only, as inferred from the $3664 \mathrm{~cm}^{-1}$ band of transmission IR spectrum of $\mathrm{Pd} / \mathrm{Na}$-Dno (Figure $5 \mathrm{~d}$ ).

Figure 6a shows the argon physisorption isotherms of $\mathrm{Pd} / \mathrm{Na}-\mathrm{Dno}$ and $\mathrm{Pd} / \mathrm{Na}-\mathrm{Z}$. Whereas the argon uptake did not change in the microporous region (below $0.1 \mathrm{p} / \mathrm{p}_{0}$ ), a notable rise in the adsorption occurred at higher relative pressures. The pore size distribution (Figure 6b), obtained from fitting the argon physisorption isotherm using the non-local density functional theory model for zeolites (NLDFT), ${ }^{67-68}$ revealed the presence of mesopores $\left(17 \mathrm{~m}^{2} / \mathrm{g}\right)$ in the non-pretreated material $(\mathrm{Pd} / \mathrm{Na}-\mathrm{Z})$, which was assigned to the roughness of the external surface of the zeolite. The distributions obtained for $\mathrm{Pd} / \mathrm{Na}-\mathrm{Zc}, \mathrm{Pd} / \mathrm{Na}-\mathrm{Zn}$ and $\mathrm{Pd} / \mathrm{Na}-\mathrm{Zo}$ suggest that individual acid pretreatments did not produce any additional porosity (Figure 6, Table S1) in the zeolite. Desilication produced additional mesopores (Table S1) with the pore diameter ranging from 2 to $10 \mathrm{~nm}(\mathrm{Pd} / \mathrm{Na}$-Dno, Figure 6). The generation of these internal defects in $\mathrm{Pd} / \mathrm{Na}$-Dno was also confirmed by the appearance of a new signal in the transmission IR spectrum (Figure 5d) corresponding to the internal terminal Si-OH groups $\left(3729 \mathrm{~cm}^{-1}\right),{ }^{52}$ which was not present in the acid pretreated samples (Figure 5a-c). More mild base treatment $(0.1 \mathrm{M})$ neither affected the pore structure of the catalyst nor improved its performance (Figure S2), whereas more severe desilication $(0.5-0.8 \mathrm{M})$ still improved the catalyst stability, but decreased its activity. 
Scanning transmission electron microscopy was employed to locate palladium species in spent $\mathrm{Pd} / \mathrm{Na}-\mathrm{Zno}$ and spent $\mathrm{Pd} / \mathrm{Na}-\mathrm{Dno}$. The comparison of secondary and transmission electron images of spent $\mathrm{Pd} / \mathrm{Na}-\mathrm{Zno}$ (Figures $7 \mathrm{a}$ and $7 \mathrm{~b}$, respectively) reveals that most of palladium nanoparticles occurred on the external surface of the zeolite, whereas in the case of spent $\mathrm{Pd} / \mathrm{Na}$-Dno the nanoparticles were located predominantly within the zeolite (Figure $7 \mathrm{c}, \mathrm{d})$. The higher stability of $\mathrm{Pd} / \mathrm{Na}-\mathrm{Dno}$ compared to other catalysts is thus achieved by the three effects of desilication: more complete removal of EFAL, stabilization of the framework aluminum and encaging of palladium nanoparticles in the constrained intracrystalline mesopores. This led to the physical separation of the well-dispersed active phase and prevented sintering, resulting in superior stability and high activity, even in the presence of steam, which is known to promote palladium aggregation. ${ }^{13,19-20}$

\subsection{Generalization of results}

The described synthetic approach can be applied to other zeolite structures as can be seen from the performance of non-modified, dealuminated and consecutively base-acid treated $\mathrm{Pd} / \mathrm{Na}-\mathrm{BEA}$ (Figure 2b) and $\mathrm{Pd} / \mathrm{Na}-\mathrm{MOR}$ (Figure 2c). Since some zeolite frameworks can exhibit different susceptibility to acid and base treatments, the post synthesis modification conditions for the zeolite beta had to be adjusted, ${ }^{69}$ whereas for mordenite and ZSM-5 an identical synthesis protocol was used. Similar to ZSM-5 (Section 3.1), neutralization of nonmodified $\mathrm{Pd} / \mathrm{BEA}$ by sodium resulted in an unstable catalyst, which lost the activity completely after $20 \mathrm{~h}$ on stream, while mildly dealuminated Pd/Na-BEA-o and consecutively desilicated and dealuminated Pd/Na-BEA-Do showed enhanced activity and stability. Similar trends were observed for $\mathrm{Pd} / \mathrm{Na}-\mathrm{MOR}$, which after base-acid treatment showed exceptional stability for over $80 \mathrm{~h}$ in the presence of steam (Figure 2c) and remained active even after hydrothermal ageing at $600^{\circ} \mathrm{C}$ (Figure S3). Finally, the stability and activity of $\mathrm{Pd} /$ zeolite catalysts prepared using the novel synthesis route do not depend on the type of chargebalancing cation $\left(\mathrm{Na}^{+}, \mathrm{K}^{+}\right.$and $\left.\mathrm{Cs}^{+}\right)$as shown for Pd/MOR-no (Figure S4). Therefore, at least three various zeolite framework types (MFI, BEA and MOR) exhibit similar behavior when consecutively loaded with palladium and a monovalent alkali cation. This implies that the presented synthetic approach is generally applicable to $\mathrm{Pd} /$ zeolite systems and can potentially be exploited for other reactions.

Table 3 summarizes the causes of metal zeolite-based catalyst deactivation and synthesis measures that can be taken against it. While acidity-induced Ostwald ripening can be mitigated by either alkali titration of the acid sites or use of high-silica support (associated 
with the difficulty of active metal impregnation), nanoparticle aggregation can be prevented by introducing a secondary network of constricted mesopores, which isolate them from each other. Finally, the active metal may be blocked or poisoned by extra-framework species, which can be initially present in the support or occur due to degradation of defect framework areas under reaction conditions. These species can be efficiently removed by selective dealumination.

\section{Conclusions}

We demonstrated a novel approach to the synthesis of sintering-resistant $\mathrm{Pd} /$ zeolite catalysts and proved its efficiency in the demanding methane oxidation reaction. Whereas deactivation of conventional $\mathrm{Pd} / \mathrm{H}-\mathrm{ZSM}-5$ catalysts is governed by sintering of palladium nanoparticles, the performance of the fully-exchanged $\mathrm{Pd} / \mathrm{Na}-\mathrm{ZSM}-5$ catalysts is sensitive to the aluminum speciation and distribution in the zeolite. Selective removal of extra-framework, surface framework and defect framework aluminum by pretreating the zeolite with a mixture of oxalic and nitric acids allowed to improve significantly the activity and stability of $\mathrm{Pd} / \mathrm{Na}$ ZSM-5. However, such catalysts continued to deactivate through palladium sintering. Desilication prior to acid dealumination allowed to more efficiently remove extra-framework aluminum and produced mesopores, which served as containers for small palladium nanoparticles, thus physically separating these entities from each other and preventing their growth. In addition to the aluminum distribution and pore structure, stability of the zeolite is an important factor. Consecutive desilication and dealumination removed primarily defect areas of the zeolite and thus gradually improved the stability of the framework aluminum, which helped to further enhance the performance of the catalyst. After adjustment of the synthesis conditions, the approach can be applied to other zeolite structures, for instance, zeolite beta and mordenite. The results show that there is a great potential for improving the efficiency of metal zeolite catalysts by rational post-synthetic modification of the support material.

Supporting Information. Textural properties of calcined Pd/ZSM-5 catalysts; XRD patterns of selected Pd/ZSM-5 catalysts; methane conversion over desilicated Pd/ZSM-5 samples; methane conversion on $\mathrm{Pd} / \mathrm{Na}-\mathrm{MOR}-\mathrm{Dno}$ before and after hydrothermal ageing and on Pd/Na-MOR-no, Pd/K-MOR-no and Pd/Cs-MOR-no.

\section{Acknowledgements}


The authors thank the Paul Scherrer Institut for financial support, Dr. Frank Krumeich (ETH Zurich) for the electron microscopy images, Dr. René Verel (ETH Zurich) for assistance with NMR measurements, Mrs. Silvia Köchli for elemental analysis and Dr. Vitaly Sushkevich (Paul Scherrer Institut) for infrared spectroscopy measurements.

\section{Competing interests}

The authors declare no competing interest.

\section{References}

1. Barnham, K.; Knorr, K.; Mazzer, M., Recent Progress Towards All-Renewable Electricity Supplies. Nat. Mater. 2015, 15, 115.

2. Gelin, P.; Primet, M., Complete Oxidation of Methane at Low Temperature over Noble Metal Based Catalysts: A Review. Appl. Catal. B: Environmental 2002, 39, 1-37.

3. Choudhary, T. V.; Banerjee, S.; Choudhary, V. R., Catalysts for Combustion of Methane and Lower Alkanes. Appl. Catal. A: General 2002, 234, 1-23.

4. Lee, J. H.; Trimm, D. L., Catalytic combustion of methane. Fuel Process. Technol. 1995, 42, 339-359.

5. Wenge, L.; Deyong, G.; Xin, X., Research Progress of Palladium Catalysts for Methane Combustion. China Petroleum Proc. Petrochem. Tech. 2012, 14, 1-9.

6. Lampert, J. K.; Kazi, M. S.; Farrauto, R. J., Palladium Catalyst Performance for Methane Emissions Abatement from Lean Burn Natural Gas Vehicles. Appl. Catal. B: Environmental 1997, 14, 211-223.

7. Grunwaldt, J. D.; vanVegten, N.; Baiker, A., Chem. Commun. 2007, 4635-4637

8. Domingos, D.; Simplicio, L. M. T.; Estrela, G. S.; dos Prazeres, M. A. G.; Brandao, S. T., Catalytic Combustion of Methane over PdO-CeO $\mathrm{Cl}_{2} / \mathrm{Al}_{2} \mathrm{O}_{3}$ and $\mathrm{PdO}-\mathrm{CeO}_{2} / \mathrm{ZrO}_{2}$ Catalysts. Stud. Surf. Sci. Catal. 2007, 167, $7-12$.

9. Gannouni, A.; Albela, B.; Zina, M. S.; Bonneviot, L., Metal Dispersion, Accessibility and Catalytic Activity in Methane Oxidation of Mesoporous Templated Aluminosilica Supported Palladium. Appl. Catal. A: General 2013, 464-465, 116-127.

10. Lapisardi, G.; Urfels, L.; Gelin, P.; Primet, M.; Kaddouri, A.; Garbowski, E.; Toppi, S.; Tena, E., Superior Catalytic Behaviour of Pt-Doped Pd Catalysts in the Complete Oxidation of Methane at Low Temperature. Catal. Today 2006, 117, 564-568.

11. Narui, K.; Yata, H.; Furuta, K.; Nishida, A.; Kohtoku, Y.; Matsuzaki, T., Effects of Addition of Pt to $\mathrm{PdO} / \mathrm{Al}_{2} \mathrm{O}_{3}$ Catalyst on Catalytic Activity for Methane Combustion and TEM Observations of Supported Particles. Appl. Catal. A: General 1999, 179, 165-173.

12. Okumura, K.; Shinohara, E.; Niwa, M., Pd Loaded on High Silica Beta Support Active for the Total Oxidation of Diluted Methane in the Presence of Water Vapor. Catal. Today 2006, 117, 577-583.

13. Park, J. H.; Kim, B.; Shin, C. H.; Seo, G.; Kim, S. H.; Hong, S. B., Methane Combustion over Pd Catalysts Loaded on Medium and Large Pore Zeolites. Top. Catal. 2009, 52, 27-34. 
14. Ruiz, J. A. C.; Oliveira, E. C.; Fraga, M. A.; Pastore, H. O., Performance of Pd Supported on Mesoporous Molecular Sieves on Methane Combustion. Catal. Commun. 2012, 25, 1-6.

15. Takeguchi, T.; Takeoh, O.; Aoyama, S.; Ueda, J.; Kikuchi, R.; Eguchi, K., Strong Chemical Interaction between $\mathrm{PdO}$ and $\mathrm{SnO}_{2}$ and the Influence on Catalytic Combustion of Methane. Appl. Catal. A: General 2003, 252, 205-214.

16. Yoshida, H.; Nakajima, T.; Yazawa, Y.; Hattori, T., Support Effect on Methane Combustion over Palladium Catalysts. Appl. Catal. B: Environmental 2007, 71, 70-79.

17. Eyssler, A.; Winkler, A.; Mandaliev, P.; Hug, P.; Weidenkaff, A.; Ferri, D., Influence of Thermally Induced Structural Changes of $2 \mathrm{wt} \% \mathrm{Pd} / \mathrm{LaFeO}_{3}$ on Methane Combustion Activity. Appl. Catal. B: Environmental 2011, 106, 494-502.

18. Descorme, C.; Gelin, P.; Lecuyer, C.; Primet, M., Palladium-Exchanged MFI-Type Zeolites in the Catalytic Reduction of Nitrogen Monoxide by Methane Influence of the Si/Al Ratio on the Activity and the Hydrothermal Stability. Appl. Catal. B: Environmental 1997, 13, 185-195.

19. Okumura, K.; Matsumoto, S.; Nishiaki, N.; Niwa, M., Support Effect of Zeolite on Methane Combustion Activity of Palladium. Appl. Catal. B: Environmental 2003, 40, 151-159.

20. Matam, S. K.; Aguirre, M. H.; Weidenkaff, A.; Ferri, D., Revisiting the Problem of Active Sites for Methane Combustion on Pd/A12O3 by Operando XANES in a Lab-Scale Fixed-Bed Reactor. J. Phys. Chem. C 2010, 114, 9439-9443.

21. Petrov, A. W.; Ferri, D.; Tarik, M.; Kröcher, O.; van Bokhoven, J. A., Deactivation Aspects of Methane Oxidation Catalysts Based on Palladium and ZSM-5. Top. Catal. 2017, 60, 123-130.

22. Kudera, S.; Maus, L.; Zanella, M.; Pelaz, B.; Zhang, Q.; Parak, W. J.; del Pino, P.; Parak, W. J., Inorganic Core-Shell Nanoparticles. In Reference Module in Materials Science and Materials Engineering, Elsevier: 2016; pp 271-284.

23. Farrusseng, D.; Tuel, A., Perspectives on Zeolite-Encapsulated Metal Nanoparticles and their Applications in Catalysis. New J. Chem. 2016, 40, 3933-3949.

24. Bum Han, K.; Takagi, C.; Ostafin, A., CHAPTER 10 Nanoreactor Catalysis. In Metal Nanoparticles for Catalysis: Advances and Applications, The Royal Society of Chemistry: 2014; pp 192-202.

25. Fodor, D.; Ishikawa, T.; Krumeich, F.; van Bokhoven, J. A., Synthesis of Single Crystal Nanoreactor Materials with Multiple Catalytic Functions by Incipient Wetness Impregnation and Ion Exchange. Adv. Mater. 2015, 27, 1919-23.

26. Jia, C.-J.; Schüth, F., Colloidal Metal Nanoparticles as a Component of Designed Catalyst. Phys. Chem. Chem. Phys. 2011, 13, 2457-2487.

27. Seo, M.-g.; Kim, S.; Lee, D.-W.; Jeong, H. E.; Lee, K.-Y., Core-Shell Structured, nano-Pd-Embedded $\mathrm{SiO}_{2}-\mathrm{Al}_{2} \mathrm{O}_{3}$ Catalyst $\left(\mathrm{Pd} @ \mathrm{SiO}_{2}-\mathrm{Al}_{2} \mathrm{O}_{3}\right.$ ) for Direct Hydrogen Peroxide Synthesis from Hydrogen and Oxygen. Appl. Catal. A: General 2016, 511, 87-94.

28. Li, S.; Tuel, A.; Meunier, F.; Aouine, M.; Farrusseng, D., Platinum Nanoparticles Entrapped in Zeolite Nanoshells as Active and Sintering-Resistant Arene Hydrogenation Catalysts. J. Catal. 2015, 332, 25-30.

29. Martínez, A.; Arribas, M. A.; Derewinski, M.; Burkat-Dulak, A., Enhanced Sulfur Resistance of Bifunctional Pd/HZSM-5 Catalyst Comprising Hierarchical Carbon-Templated Zeolite. Appl. Catal. A: General 2010, 379, 188-197. 
30. Cargnello, M.; Delgado Jaen, J. J.; Hernandez Garrido, J. C.; Bakhmutsky, K.; Montini, T.; Calvino Gamez, J. J.; Gorte, R. J.; Fornasiero, P., Exceptional Activity for Methane Combustion over Modular $\mathrm{Pd} @ \mathrm{CeO}_{2}$ Subunits on Functionalized $\mathrm{Al}_{2} \mathrm{O}_{3}$. Science 2012, 337, 713-7.

31. Ali, S.; Al-Marri, M. J.; Abdul Monem, A. G.; Arafat, Y. I.; Khader, M. M., A Comparative Study of the Effects of Water on Methane Oxidation over $\mathrm{Pd} @ \mathrm{CeO}_{2} / \mathrm{Al}_{2} \mathrm{O}_{3}$ and $\mathrm{Pd} @ \mathrm{TiO}_{2} / \mathrm{Al}_{2} \mathrm{O}_{3}$ Catalysts, $4^{\text {th }}$ International Gas Processing Symposium, 2015; pp 89-97.

32. Zhang, S.; Chen, C.; Cargnello, M.; Fornasiero, P.; Gorte, R. J.; Graham, G. W.; Pan, X., Dynamic Structural Evolution of Supported Palladium-Ceria Core-Shell Catalysts Revealed by in situ Electron Microscopy. Nat. Commun. 2015, 6, 7778.

33. Weitkamp, J., Zeolites and Catalysis. Solid State Ionics 2000, 131, 175-188.

34. Moller, K.; Bein, T., Mesoporosity - A New Dimension for Zeolites. Chem. Soc. Rev. 2013, 42, 36893707.

35. Zhu, H.; Liu, Z.; Kong, D.; Wang, Y.; Yuan, X.; Xie, Z., Synthesis of ZSM-5 with Intracrystal or Intercrystal Mesopores by Polyvinyl Butyral Templating Method. J. Colloid Interface Sci. 2009, 331, 432-8.

36. Lutz, W.; Shutilov, R. A.; Gavrilov, V. Y., Pore Structure of USY Zeolites in Dependence on Steaming Condition. Z. Anorg. Allg. Chem. 2014, 640, 577-581.

37. Fodor, D.; Krumeich, F.; Hauert, R.; van Bokhoven, J. A., Differences between Individual ZSM-5 Crystals in Forming Hollow Single Crystals and Mesopores during Base Leaching. Chem. Eur. J. 2015, 21, 6272-7.

38. Milina, M.; Mitchell, S.; Crivelli, P.; Cooke, D.; Pérez-Ramírez, J., Mesopore Quality Determines the Lifetime of Hierarchically Structured Zeolite Catalysts. Nat. Commun. 2014, 5, 3922.

39. Li, X.; Prins, R.; van Bokhoven, J. A., Synthesis and Characterization of Mesoporous Mordenite. $J$. Catal. 2009, 262, 257-265.

40. Giudici, R.; Kouwenhoven, H. W.; Prins, R., Comparison of Nitric and Oxalic Acid in the Dealumination of Mordenite. Appl. Catal. A: General 2000, 203, 101-110.

41. Janssen, A. H.; Koster, A. J.; Jong, K. P. d., Three-Dimensional Transmission Electron Microscopic Observations of Mesopores in Dealuminated Zeolite Y. Angew. Chem., Int. Ed. 2001, 40, 1102-1104.

42. Sazama, P.; Sobalik, Z.; Dedecek, J.; Jakubec, I.; Parvulescu, V.; Bastl, Z.; Rathousky, J.; Jirglova, H., Enhancement of Activity and Selectivity in Acid-Catalyzed Reactions by Dealuminated Hierarchical Zeolites. Angew. Chem., Int. Ed. 2013, 52, 2038-41.

43. Yeh, C. Y.; Song, R.; Gaffney, A. M.; Langner, T.; Margolis, M. J., Catalysts Useful for the Alkylation of Aromatic Hydrocarbons. International patent application WO 2010/082963, 2010.

44. Maeda, H.; Kinoshita, Y.; Reddy, K. R.; Muto, K.; Komai, S.; Katada, N.; Niwa, M., Activity of Palladium Loaded on Zeolites in the Combustion of Methane. Appl. Catal. A: General 1997, 163, 59-69.

45. Niwa, M.; Nakatsuji, T., Japanese Patent 07241470, 1995.

46. Petrov, A. W.; Ferri, D.; Nachtegaal, M.; Krumeich, F.; van Bokhoven, J. A.; Kröcher, O., Stable Complete Methane Oxidation over Palladium Based Zeolite Catalysts. Nat. Commun. 2018, 9, 2545.

47. Homeyer, S. T.; Sachtler, W. M. H., Elementary Steps in the Formation of Highly Dispersed Palladium in NaY. J. Catal. 1989, 117, 91-101. 
48. Zhang, Z.; Mestl, G.; Knözinger, H.; Sachtler, W. M. H., Effects of Calcination Program and Rehydration on Palladium Dispersion in Zeolites NaY and 5A. Appl. Catal. A: General 1992, 89, 155-168.

49. Pommier, B.; Gelin, P., On the Nature of Pd Species Formed upon Exchange of H-ZSM-5 with $\mathrm{Pd}\left(\mathrm{NH}_{3}\right)_{4}{ }^{2+}$ and Calcination in $\mathrm{O}_{2}$. Phys. Chem. Chem. Phys. 1999, 1, 1665-1672.

50. Cullis, C. F.; Nevell, T. G.; Trimm, D. L., Role of the Catalyst Support in the Oxidation of Methane over Palladium. J. Chem. Soc., Faraday Trans. 1972, 1, 1406.

51. Chen, X.; Cheng, Y.; Seo, C. Y.; Schwank, J. W.; McCabe, R. W., Aging, Re-Dispersion, and Catalytic Oxidation Characteristics of Model $\mathrm{Pd} / \mathrm{Al}_{2} \mathrm{O}_{3}$ Automotive Three-Way Catalysts. Appl. Catal. B: Environmental 2015, 163, 499-509.

52. Omegna, A.; Vasic, M.; van Bokhoven, J. A.; Pirngruber, G.; Prins, R., Dealumination and Realumination of Microcrystalline Zeolite Beta: an XRD, FTIR and Quantitative Multinuclear (MQ) MAS NMR Study. Phys. Chem. Chem. Phys. 2004, 6, 447.

53. Müller, M.; Harvey, G.; Prins, R., Comparison of the Dealumination Of Zeolites Beta, Mordenite, ZSM-5 and Ferrierite by Thermal Treatment, Leaching with Oxalic Acid and Treatment with $\mathrm{SiCl}_{4}$ by ${ }^{1} \mathrm{H},{ }^{29} \mathrm{Si}$ and ${ }^{27}$ Al MAS NMR. Micropor. Mesopor. Mater. 2000, 34, 135-147.

54. Okumura, K.; Yoshimoto, R.; Uruga, T.; Tanida, H.; Kato, K.; Yokota, S.; Niwa, M., EnergyDispersive XAFS Studies on the Spontaneous Dispersion of PdO and the formation of stable Pd Clusters in Zeolites. J. Phys. Chem. B 2004, 108, 6250-6255.

55. Kharas, K. C. C. Catalyst Support Having Zeolite with High Sodium Back Ion-Exchange Capacity and Catalysts Made Therefrom. US 6235255, 2001.

56. Sazama, P.; Wichterlova, B.; Dedecek, J.; Tvaruzkova, Z.; Musilova, Z.; Palumbo, L.; Sklenak, S.; Gonsiorova, O., FTIR and ${ }^{27}$ Al MAS NMR Analysis of the Effect of Framework Al- and Si-Defects in Microand Micro-Mesoporous H-ZSM-5 on Conversion of Methanol to Hydrocarbons. Micropor. Mesopor. Mater. 2011, 143, 87-96.

57. Isernia, L. F., FTIR Study of the Relation, Between Extra-Framework Aluminum Species and the Adsorbed Molecular Water, and its Effect on the Acidity in ZSM-5 Steamed Zeolite. Mater. Res. 2013, 16, 792802.

58. Jia, C.; Massiani, P.; Barthomeuf, D., Characterization by Infrared and Nuclear Marnetic Resonance Specrtoscopies of Calcined Beta Zeolite. J. Chem. Soc., Faraday Trans. 1993, 89, 3659-3665.

59. Woolery, G. L.; Kuehl, G. H.; Timken, H. C.; Chester, A. W.; Vartuli, J. C., On the Nature of Framework Brønsted and Lewis Acid Sites in ZSM-5. Zeolites 1997, 19, 288-296.

60. Coster, D.; Blumenfeld, A. L.; Fripiat, J. J., Lewis Acid Sites and Surface Aluminum in Aluminas and Zeolites: A High-Resolution NMR Study. J. Phys. Chem. 1994, 98, 6201-6211.

61. Wouters, B. H.; Chen, T. H.; Grobet, P. J., Reversible Tetrahedral-Octahedral Framework Aluminum Transformation in Zeolite Y. J. Amer. Chem. Soc. 1998, 120, 11419-11425.

62. Kiricsi, I.; Flego, C.; Pazzuconi, G.; Parker, W. O., Jr.; Millini, R.; Perego, C.; Bellussi, G., Progress toward Understanding Zeolite-beta Acidity: An IR and ${ }^{27}$ Al NMR Spectroscopic Study. J. Phys. Chem. 1994, 98, 4627-4634.

63. Omegna, A.; van Bokhoven, J. A.; Prins, R., Flexible Aluminum Coordination in Alumino-Silicates. Structure of Zeolite H-USY and Amorphous Silica-Alumina. J. Phys. Chem. B 2003, 107, 8854-8860. 
64. van Bokhoven, J. A.; Roest, A. L.; Koningsberger, D. C.; Miller, J. T.; Nachtegaal, G. H.; Kentgens, A. P. M., Changes in Structural and Electronic Properties of the Zeolite Framework Induced by Extraframework Al and La in H-USY and La(x)NaY: A ${ }^{29} \mathrm{Si}$ and ${ }^{27} \mathrm{Al}$ MAS NMR and ${ }^{27} \mathrm{Al}$ MQ MAS NMR Study. J. Phys. Chem. $B$ 2000, 104, 6743-6754.

65. Simone, D. O.; Kennelly, T.; Brungard, N. L.; Farrauto, R. J., Reversible Poisoning of Palladium Catalysts for Methane Oxidation. Appl. Catal. 1991, 70, 87-100.

66. Argyle, M. D.; Bartholomew, C. H., Heterogeneous Catalyst Deactivation and Regeneration: A Review. Catalysts 2015, 5, 145.

67. Cychosz, K. A.; Guillet-Nicolas, R.; Garcia-Martinez, J.; Thommes, M., Recent Advances in the Textural Characterization of Hierarchically Structured Nanoporous Materials. Chem. Soc. Rev. 2017, 46, 389414.

68. Landers, J.; Gor, G. Y.; Neimark, A. V., Density Functional Theory Methods for Characterization of Porous Materials. Colloids Surf., A 2013, 437, 3-32.

69. Verboekend, D.; Vilé, G.; Pérez-Ramírez, J., Mesopore Formation in USY and Beta Zeolites by Base Leaching: Selection Criteria and Optimization of Pore-Directing Agents. Cryst. Growth Des. 2012, 12, 31233132 . 


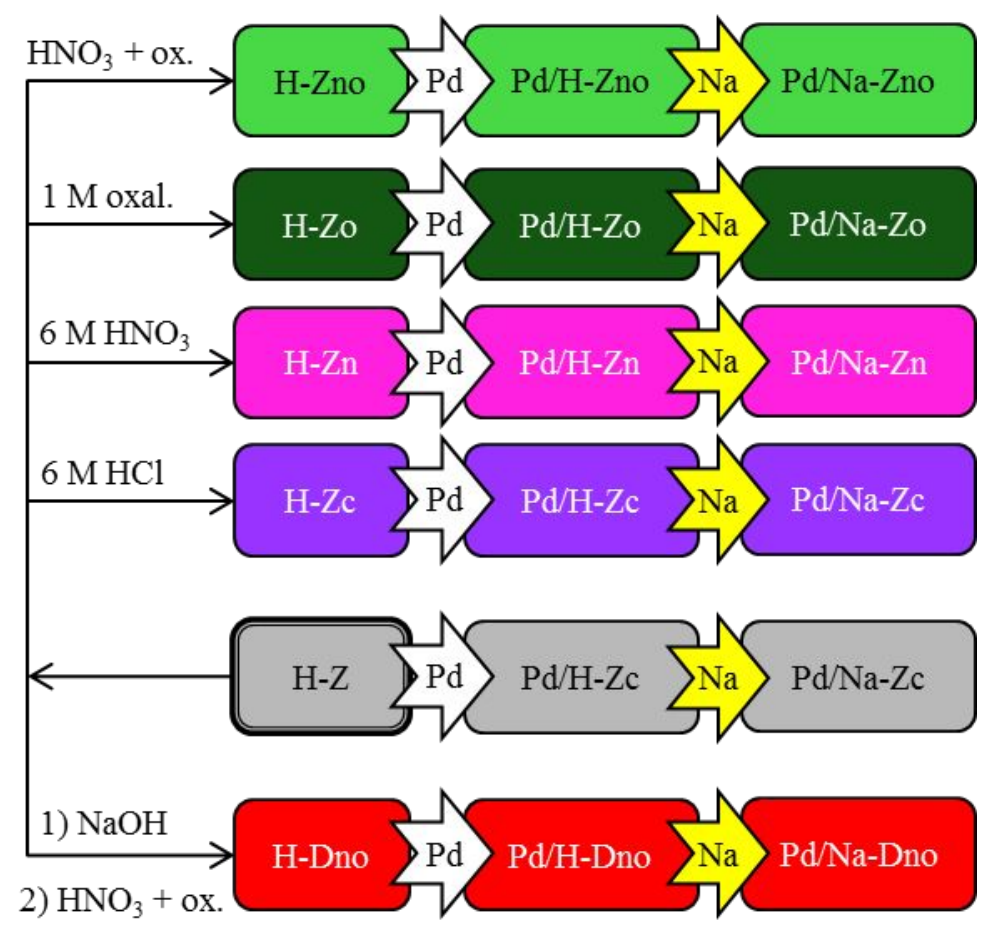

Figure 1. Overview of the various post-synthesis modifications of ZSM-5 (Clariant SM-27, $\mathrm{Si} / \mathrm{Al}=13, \mathrm{H}$-form, calcined at $500{ }^{\circ} \mathrm{C}$ for $2 \mathrm{~h}$ ). Zeolite modification was carried out prior to palladium and sodium exchange. Acid treatments were performed at $80{ }^{\circ} \mathrm{C}$ under reflux for 4 h. Base treatment was performed at $65^{\circ} \mathrm{C}$ for $30 \mathrm{~min}$. 

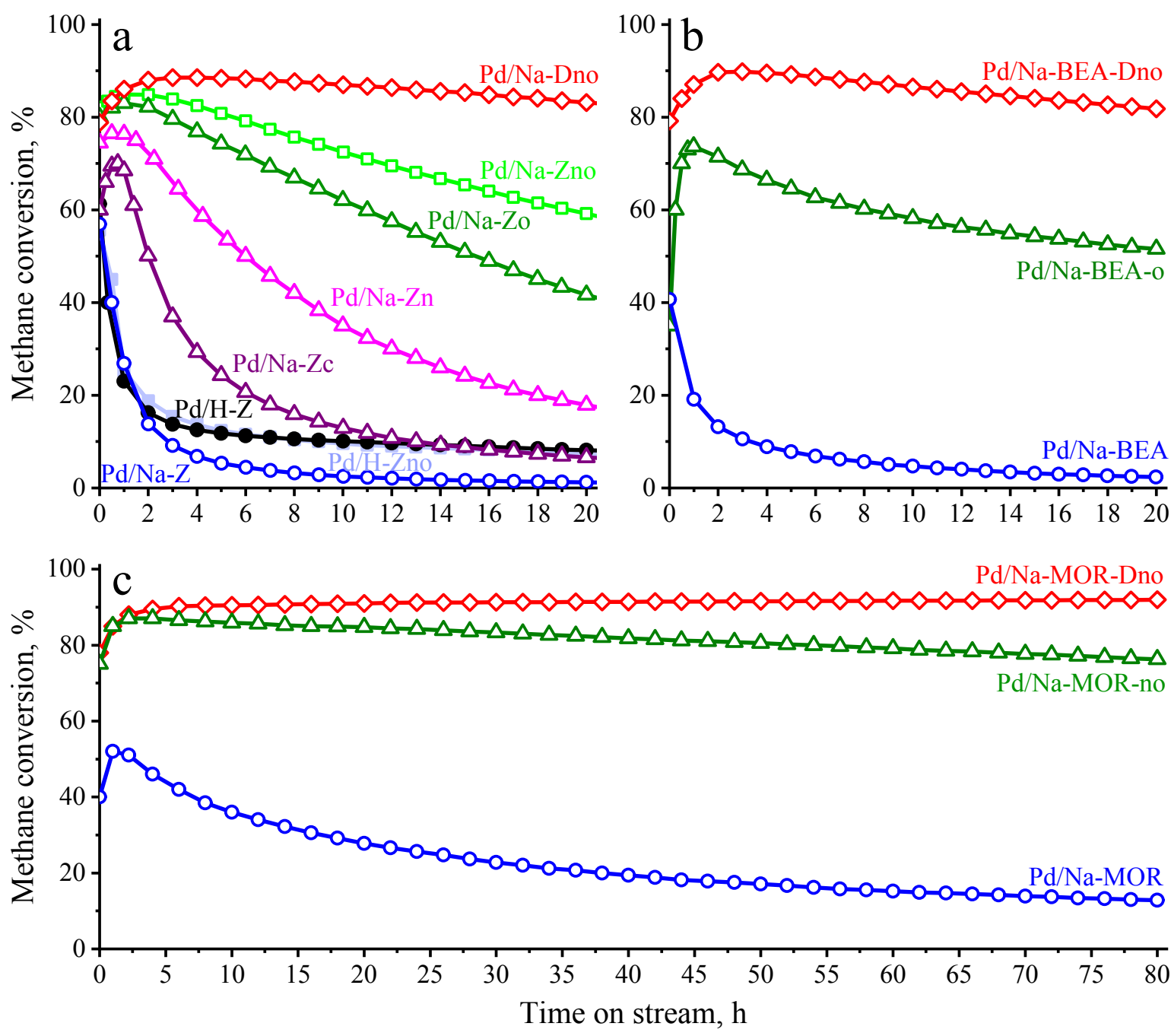

Figure 2. Methane conversion over (a) Pd/ZSM-5, (b) Pd/Na-BEA and (c) Pd/Na-MOR. Conditions: 1 vol. $\% \mathrm{CH}_{4}, 4$ vol. $\% \mathrm{O}_{2}, 5$ vol. $\% \mathrm{H}_{2} \mathrm{O}$, bal $\mathrm{N}_{2}, 410{ }^{\circ} \mathrm{C}$. Steam was added to the feed at $\mathrm{t}=0$. 

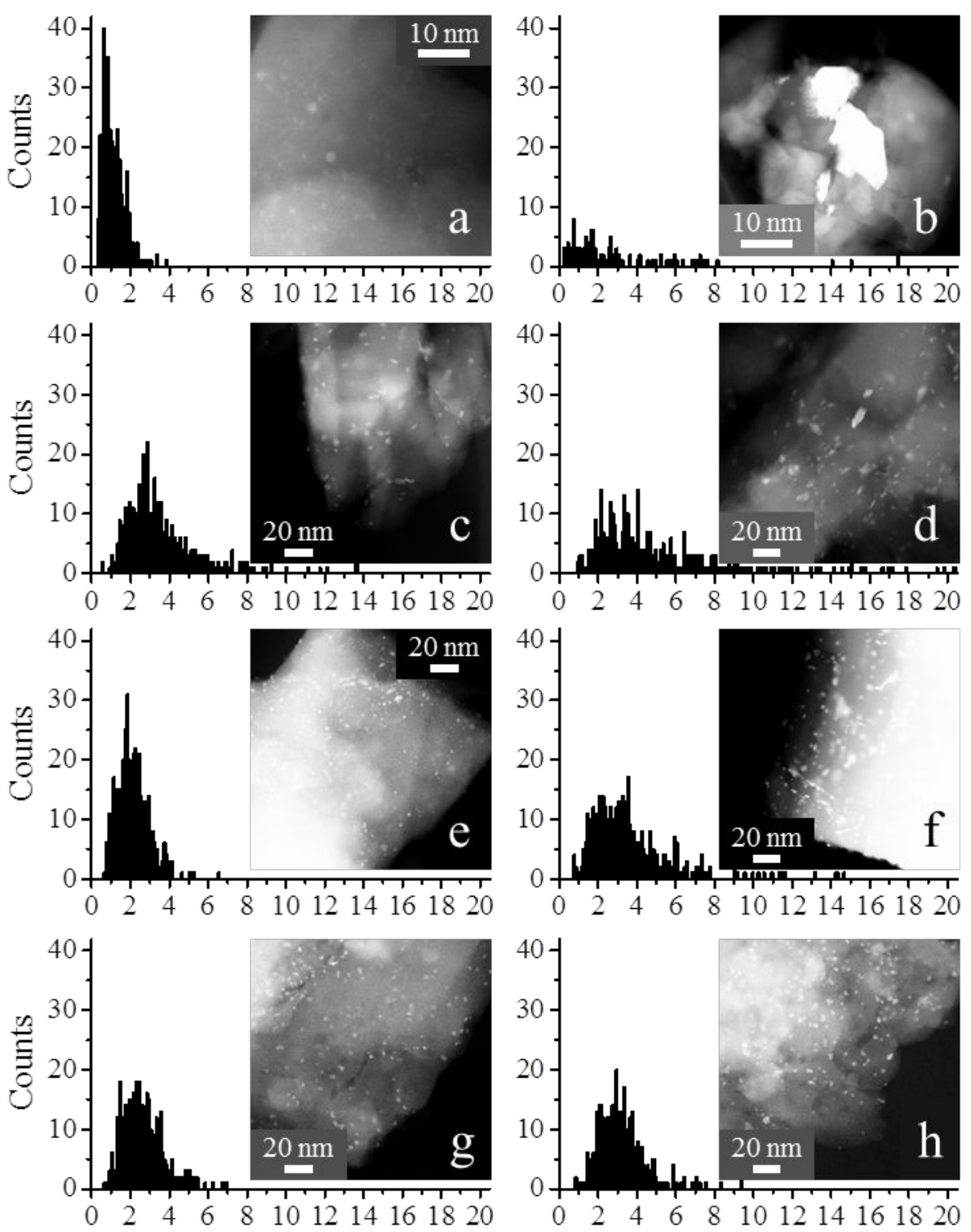

Particle size, $\mathrm{nm}$

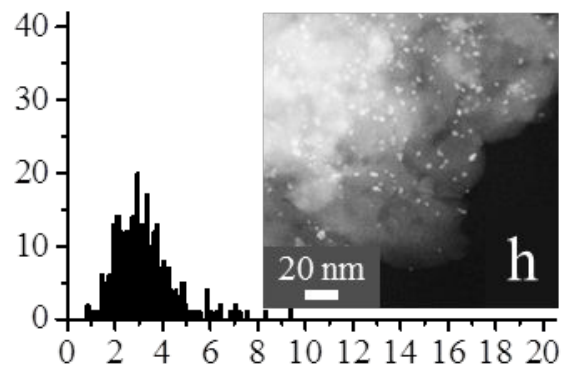

Particle size, $\mathrm{nm}$

Figure 3. Scanning transmission electron micrographs (STEM) and the corresponding palladium particle size distributions of $(a, b)$ fresh and spent $\mathrm{Pd} / \mathrm{H}-\mathrm{Z},(\mathrm{c}, \mathrm{d})$ fresh and spent $\mathrm{Pd} / \mathrm{Na}-\mathrm{Z}$, (e,f) fresh and spent Pd/Na-Zno and (g,h) fresh and spent Pd/Na-Dno, respectively. Distributions were obtained from the analysis of 12 STEM images of each sample. Spent catalysts have been aged in a flow containing 1 wt. $\% \mathrm{CH}_{4}, 4$ vol. $\% \mathrm{O}_{2}, 5$ vol. $\% \mathrm{H}_{2} \mathrm{O}$, bal $\mathrm{N}_{2}$ at $420^{\circ} \mathrm{C}$ for $20 \mathrm{~h}$. 

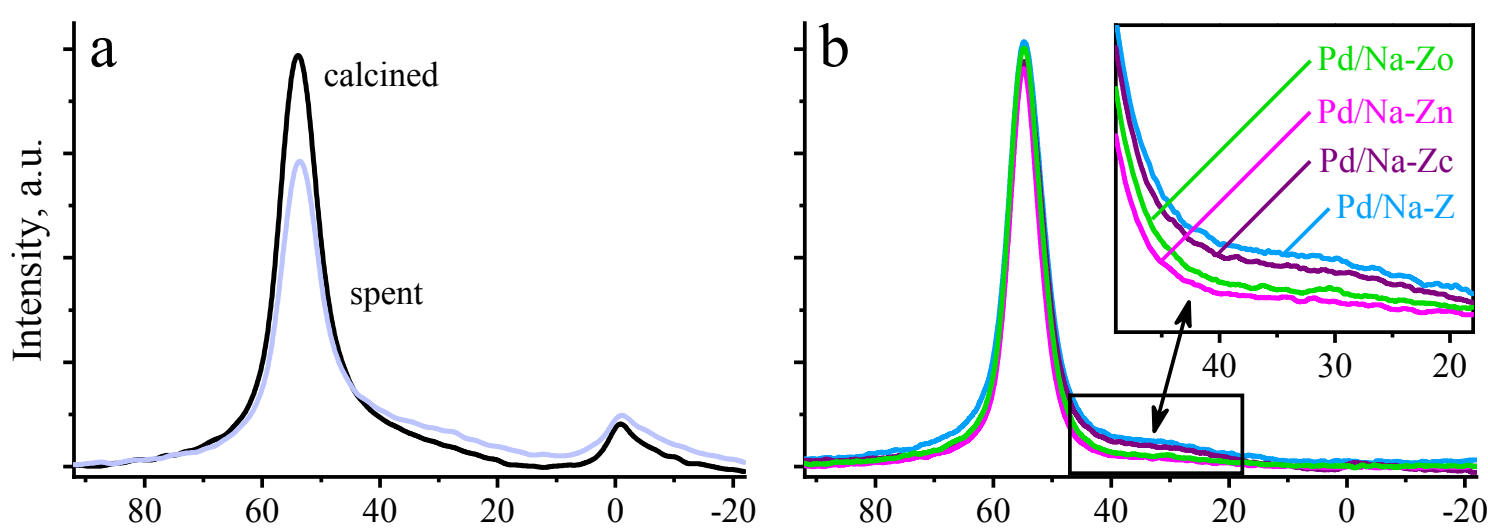

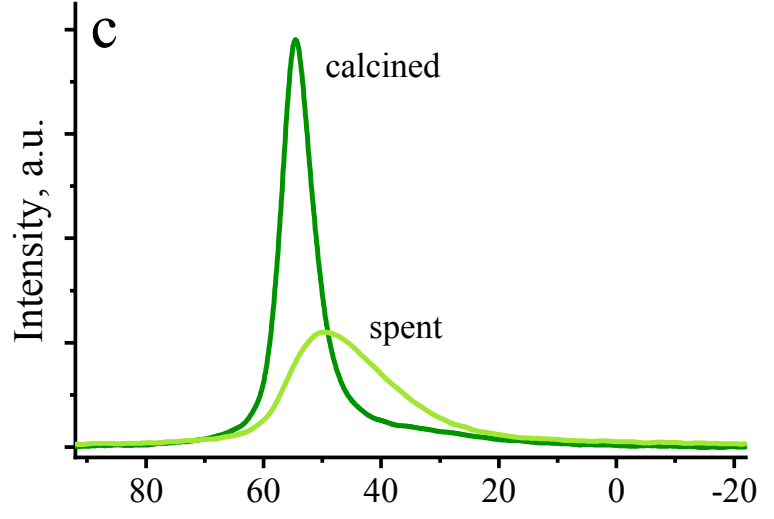

Chemical shift, ppm

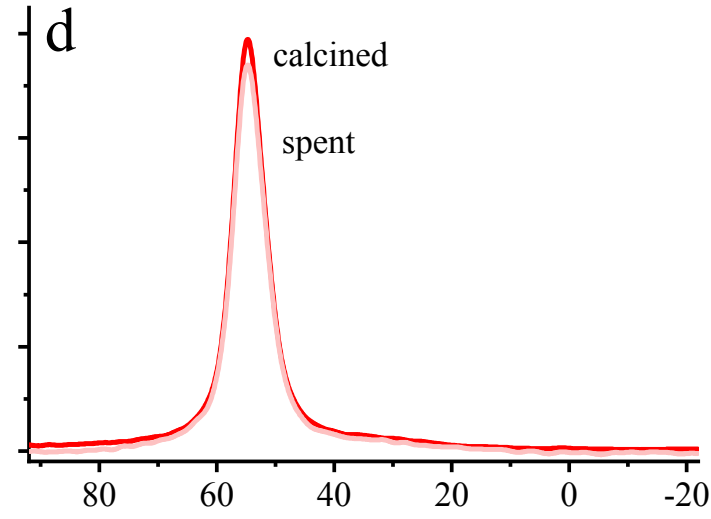

Chemical shift, ppm

Figure 4. ${ }^{27} \mathrm{Al}$ MAS NMR spectra of (a) calcined and spent $\mathrm{Pd} / \mathrm{H}-\mathrm{Z}$, (b) calcined $\mathrm{Pd} / \mathrm{Na}-\mathrm{Z}$, $\mathrm{Pd} / \mathrm{Na}-\mathrm{Zc}, \mathrm{Pd} / \mathrm{Na}-\mathrm{Zo}$ and $\mathrm{Pd} / \mathrm{Na}-\mathrm{Zn}$, (c) calcined and spent $\mathrm{Pd} / \mathrm{Na}-\mathrm{Zno}$ and (d) calcined and spent $\mathrm{Pd} / \mathrm{Na}$-Dno. 


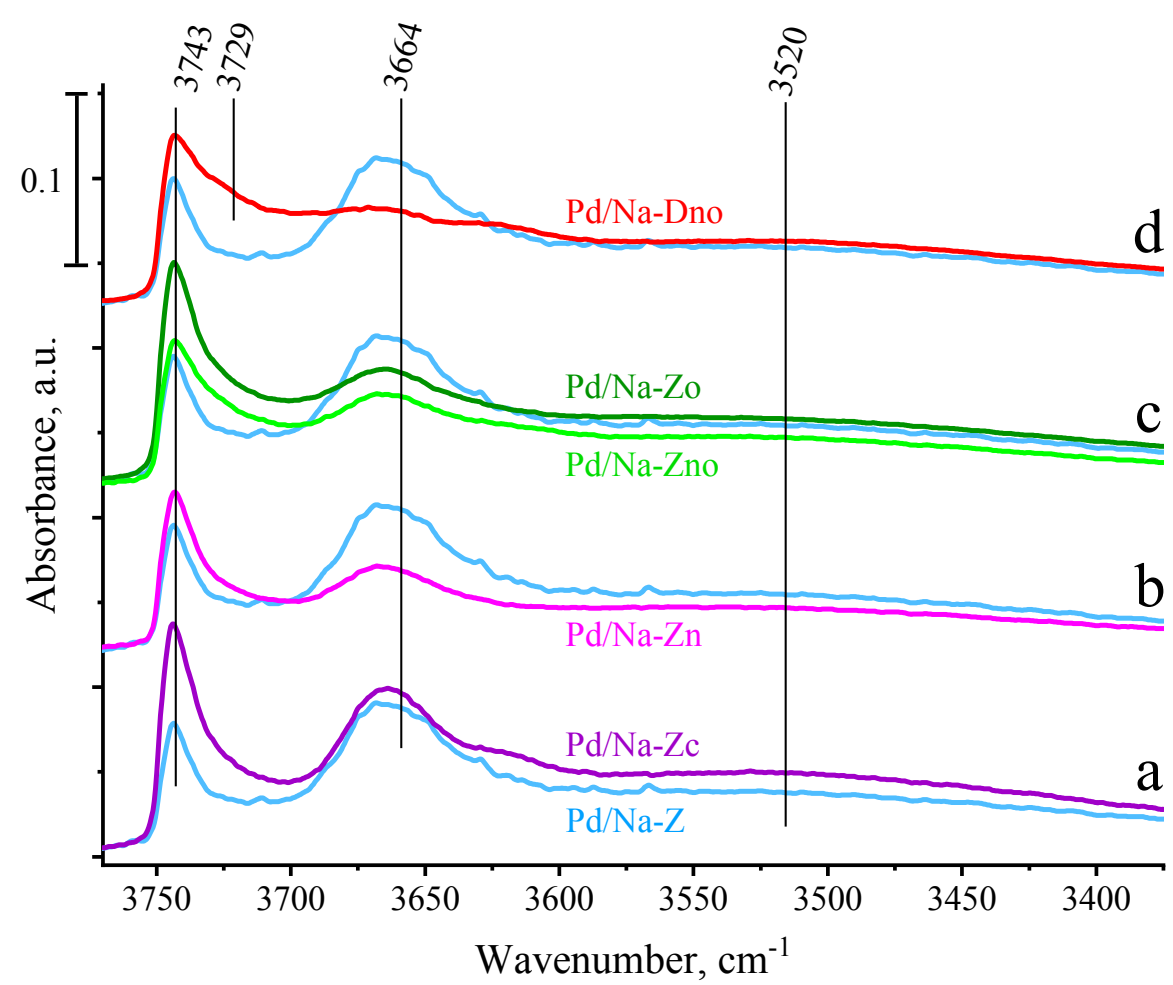

Figure 5. Transmission IR spectra of variously modified Pd/Na-ZSM-5 catalysts. The spectra are offset for clarity and are compared to the spectrum of $\mathrm{Pd} / \mathrm{Na}-\mathrm{Z}$ as the reference. 

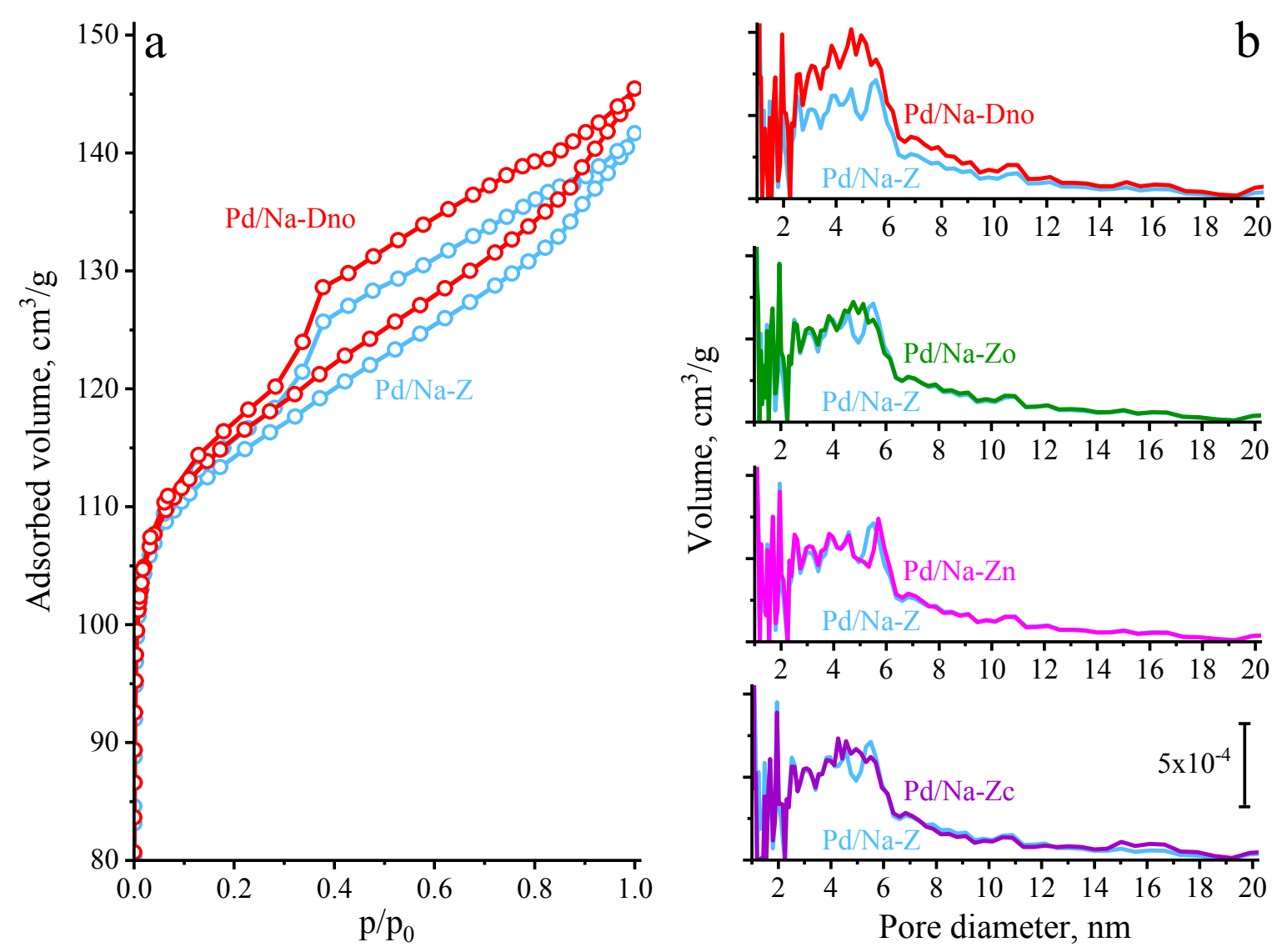

Figure 6. (a) Argon physisorption isotherms of $\mathrm{Pd} / \mathrm{Na}-\mathrm{Z}$ and $\mathrm{Pd} / \mathrm{Na}-\mathrm{Dno}$ and (b) differential pore volume of the non-pretreated and variously pretreated Pd/Na-ZSM-5 catalysts. 

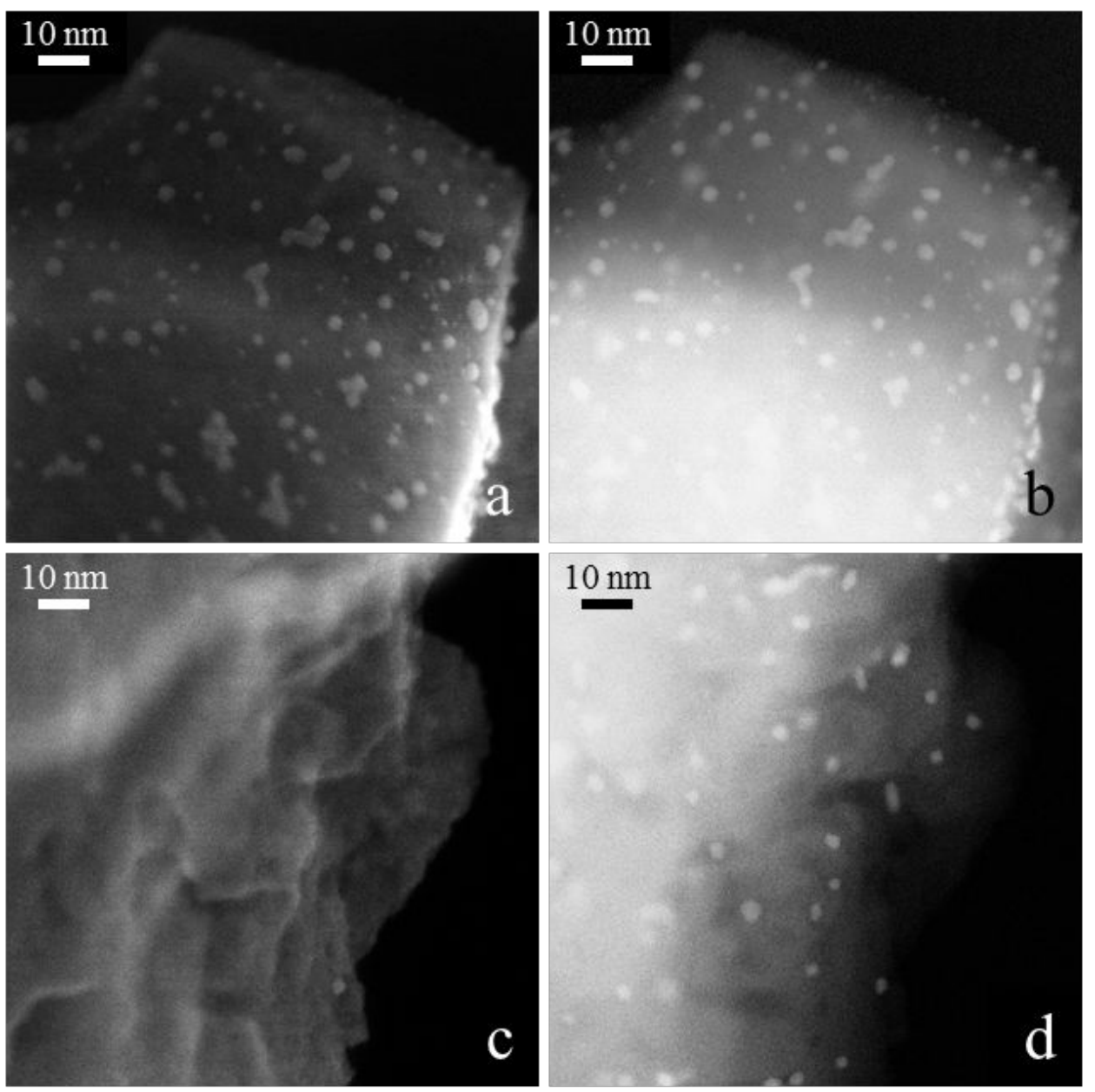

Figure 7. Secondary electron image of (a) spent $\mathrm{Pd} / \mathrm{Na}-\mathrm{Zno}$ and (c) spent $\mathrm{Pd} / \mathrm{Na}-\mathrm{Dno}$, scanning transmission electron image of (b) spent Pd/Na-Zno and (d) spent Pd/Na-Dno. Detection of secondary electrons allows the selective analysis of the external surface of the sample, while the transmitted electrons of the scanning electron image probe the whole sample depth and is thus ambiguous on the location of the nano-particles. 
Table 1. Palladium average particle size and surface area derived from STEM

\begin{tabular}{|l|c|c|c|c|c|c|}
\hline \multicolumn{1}{|c|}{ Sample } & \multicolumn{2}{c|}{$\begin{array}{c}\text { Average Pd particle } \\
\text { diameter, nm }\end{array}$} & \multicolumn{2}{c|}{$\begin{array}{c}\text { Pd surface area } \\
\text { from STEM, m} \mathbf{~}^{2} \mathbf{g}\end{array}$} & \multicolumn{2}{c|}{$\begin{array}{c}\text { Methane } \\
\text { conversion }\end{array}$} \\
& calcined & spent & calcined & spent & calcined & spent \\
\hline $\mathrm{Pd} / \mathrm{H}-\mathrm{Z}$ & 1.1 & 3.1 & 420 & 70 & 60 & 10 \\
\hline $\mathrm{Pd} / \mathrm{Na}-\mathrm{Z}$ & 3.5 & 5.1 & 120 & 70 & 60 & 1 \\
\hline $\mathrm{Pd} / \mathrm{Na}-\mathrm{Zno}$ & 2.1 & 3.6 & 280 & 110 & 80 & 62 \\
\hline $\mathrm{Pd} / \mathrm{Na}-\mathrm{Dno}$ & 2.4 & 2.6 & 270 & 280 & 79 & 83 \\
\hline
\end{tabular}

${ }^{\mathrm{a}}$ conditions: 1 vol. $\% \mathrm{CH}_{4}, 4$ vol. $\% \mathrm{O}_{2}, 5$ vol. $\% \mathrm{H}_{2} \mathrm{O}, \mathrm{N}_{2}$ bal. $420{ }^{\circ} \mathrm{C}$. 
Table 2. Chemical composition of Pd/ZSM-5 catalysts and effect of post-synthesis modifications of the zeolite.

\begin{tabular}{|c|c|c|c|c|c|c|}
\hline Sample & $\begin{array}{l}\mathrm{Si} / \mathrm{Al} \\
\text { ratio }\end{array}$ & $\begin{array}{c}\text { Pd, } \\
\text { wt. \% }\end{array}$ & $\begin{array}{l}\text { Na, } \\
\text { wt. \% }\end{array}$ & $\begin{array}{l}\text { Formal } \\
\text { exchange } \\
\text { level }^{\mathrm{a}}, \%\end{array}$ & $\begin{array}{l}\text { EFAL } \\
\text { a.u. }\end{array}$ & $\begin{array}{l}\text { Effect of post-synthesis } \\
\text { modifications }\end{array}$ \\
\hline $\mathrm{Pd} / \mathrm{H}-\mathrm{Z}$ & 11.8 & 0.98 & $<0.01$ & 15 & - & - \\
\hline $\mathrm{Pd} / \mathrm{H}-\mathrm{Zno}$ & 14.6 & 0.97 & $<0.01$ & 19 & - & - \\
\hline $\mathrm{Pd} / \mathrm{Na}-\mathrm{Z}$ & 11.9 & 0.89 & 1.8 & 81 & 4.9 & - \\
\hline $\mathrm{Pd} / \mathrm{Na}-\mathrm{Zc}$ & 13.3 & 0.96 & 1.6 & 84 & 4.2 & bulk dealumination \\
\hline $\mathrm{Pd} / \mathrm{Na}-\mathrm{Zn}$ & 14.4 & 0.91 & 1.8 & 93 & 1.7 & $\begin{array}{l}\text { bulk dealumination, } \\
\text { dissolution of } \mathrm{Si}-\mathrm{OH} \\
\text { groups }\end{array}$ \\
\hline $\mathrm{Pd} / \mathrm{Na}-\mathrm{Zo}$ & 13.4 & 0.89 & 1.8 & 91 & 1.7 & surface dealumination \\
\hline $\mathrm{Pd} / \mathrm{Na}-\mathrm{Zno}$ & 15.0 & 0.96 & 1.7 & 88 & 1.6 & $\begin{array}{l}\text { surface and bulk } \\
\text { dealumination, dissolution } \\
\text { of Si-OH groups }\end{array}$ \\
\hline $\mathrm{Pd} / \mathrm{Na}-\mathrm{Dno}$ & 14.8 & 0.92 & 1.7 & 93 & 0.6 & $\begin{array}{l}\text { formation of mesopores, } \\
\text { surface and bulk } \\
\text { dealumination, dissolution } \\
\text { of Si-OH groups }\end{array}$ \\
\hline
\end{tabular}

acalculated using the formal equation $\left(2 \times n_{P d}+n_{N a}\right) / n_{A l}$, assuming $\mathrm{Pd}^{2+}$ species.

bobtained from integrating peak at $3664 \mathrm{~cm}^{-1}$ of IR spectra shown in Figure 5. 
Table 3. Causes for metal-zeolite catalyst deactivation and countering synthetic strategies

\begin{tabular}{|l|l|l|}
\hline Deactivation cause & Synthesis modification & Effect \\
\hline $\begin{array}{l}\text { Ostwald ripening induced } \\
\text { by support acidity }\end{array}$ & $\begin{array}{l}\text { titration of acid sites with alkali46 } \\
\text { or use of high-silica zeolite }\end{array}$ & removal of acid sites \\
\hline $\begin{array}{l}\text { metal particle } \\
\text { agglomeration }\end{array}$ & mild desilication & $\begin{array}{l}\text { isolation of nanoparticles } \\
\text { in constricted mesopores }\end{array}$ \\
\hline $\begin{array}{l}\text { self-poisoning by extra- } \\
\text { framework species }\end{array}$ & selective dealumination & $\begin{array}{l}\text { removal of extra- } \\
\text { framework and defect } \\
\text { framework species }\end{array}$ \\
\hline
\end{tabular}


Table of Content graph

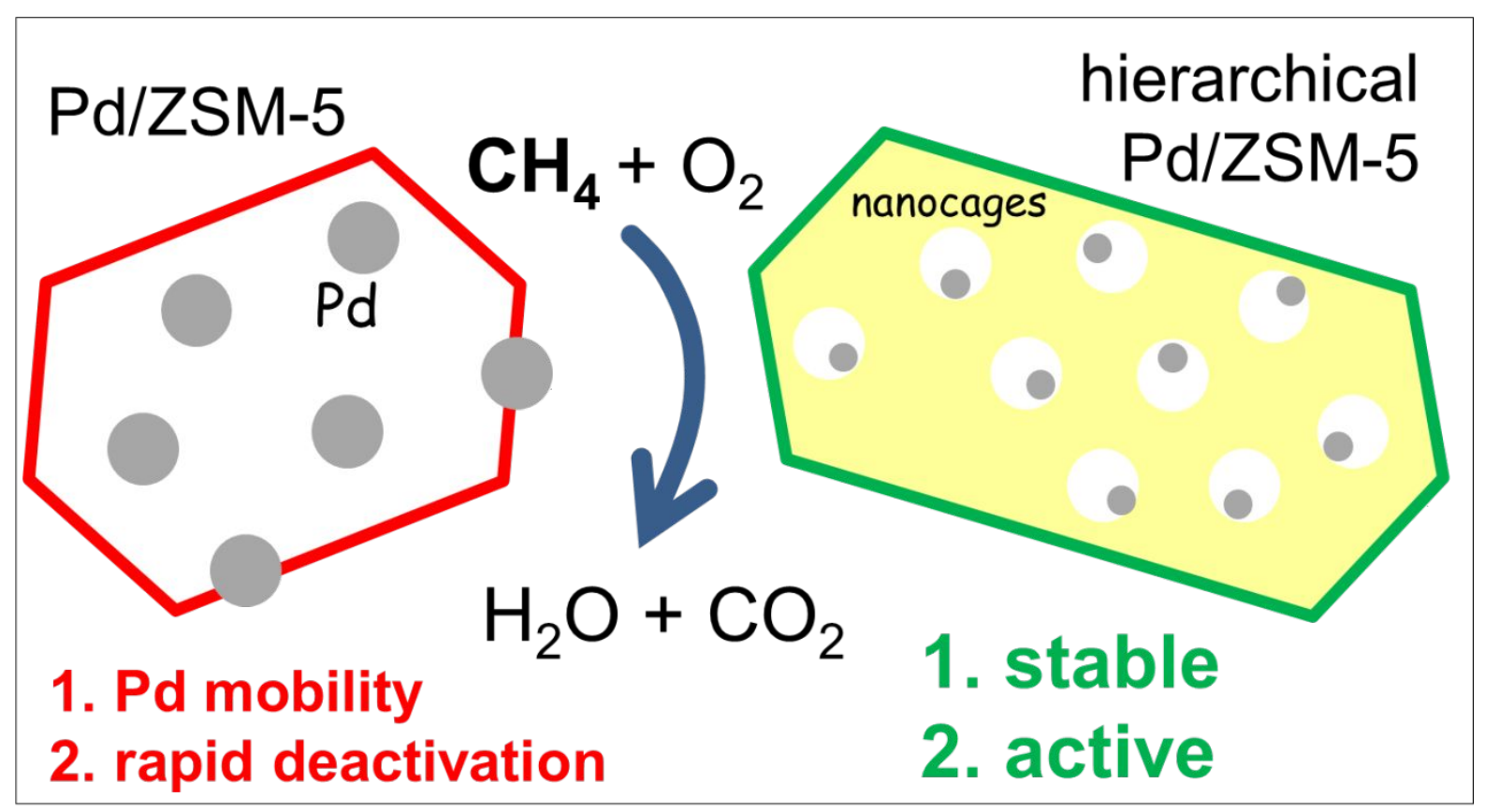

